\title{
Modeling and Shaping of the DC-Side Admittance of a Modular Multilevel Converter under Closed-Loop Voltage Control
}

\author{
Mehrdad Nahalparvari ${ }^{\circledR}$, Student Member, IEEE, Mohsen Asoodar ${ }^{(0)}$, Student Member, IEEE, \\ Luca Bessegato ${ }^{\circledR}$, Staffan Norrga ${ }^{\circledR}$, Member, IEEE, and Hans-Peter Nee ${ }^{\circledR}$, Fellow, IEEE
}

\begin{abstract}
The dc-side admittance of a modular multilevel converter can be used in assessing the stability of the dc system by means of impedance-based stability criteria. An accurate mathematical representation of the small-signal admittance can be given using harmonic linearization. To this end, the effect of the internal dynamics of the converter, e.g., the circulating current, the converter control scheme, and the controller parameters on the admittance of the converter should be analyzed. In this paper, a linear analytical model for the dc-side admittance of the converter is derived based on a combination of harmonic linearization and frequency-domain representation which incorporates different control schemes. Moreover, an admittance model is given for the closed-loop voltage control mode of the converter, where the ideal insertion indices are applied. To this end, the impact of an arm-balancing controller and its parameters on the dc-side admittance of the converter is investigated. Finally, experiments are carried out on a downscaled prototype to validate the accuracy of the analytical model.
\end{abstract}

Index Terms-Modular multilevel converter (MMC), converter control, stability, admittance modeling, frequency domain analysis, harmonic linearization.

\section{INTRODUCTION}

$\mathbf{M}$ ODULAR multilevel converters (MMCs) [1], [2] have become the prevalent technology in high-power applications by virtue of their modularity, scalability, low distortions, and high efficiency. Applications of MMCs include (but are not limited to) voltage source converter (VSC) based HVDC transmission [3], electric railway traction systems [4], and medium voltage motor drives [5]. The complex internal dynamics of the MMC topology, e.g., the submodule capacitor voltage fluctuations and the circulating currents, have motivated research on the admittance modeling and the small-signal stability analysis of these converters in an effort to address the arising instability and harmonic resonance problems in the field [6]-[8].

Many point-to-point VSC-HVDC links are already in operation facilitating, e.g., the integration of offshore wind farm power generation to the ac grid [9]. The expansion of existing HVDC systems into multiterminal grids would increase the reliability and offer redundancy to the overall system.

M. Nahalparvari, M. Asoodar, L. Bessegato, S. Norrga and H.-P. Nee are with the School of Electrical Engineering and Computer Science, KTH Royal Institute of Technology, 10044 Stockholm, Sweden (email: mnah@kth.se; asoodar@kth.se; lucabe@kth.se; norrga@kth.se; hansi@kth.se).
Nonetheless, resonances could occur within the dc system leading to harmonic instability [7], [10]. The dc networkrelated stability of a multiterminal VSC-HVDC system can be studied using the passivity-based stability assessment [11], net-damping criterion [12], or the impedance-based stability criterion [13]. For the latter, the impedance (or the admittance) of the converter seen from the dc-side should be derived. Modeling this admittance is not straightforward since the dynamic behavior of the MMC is highly nonlinear. Notwithstanding, harmonic linearization techniques can prove useful in developing a small-signal admittance model for a multiharmonic response system such as an MMC [14].

Research on the ac-side admittance modeling of the MMCs is abundant [15]-[20]. Some attempts have also been made to model the dc-side admittance of an MMC. A method based on nodal voltage analysis is proposed in [21] to calculate the dc-side loop impedance for a line commutated converterbased hybrid HVDC transmission system. In [22], the dcside impedance has been derived using the harmonic statespace method which requires significant matrix manipulation. Nonetheless, the study only considers the internal dynamics of the MMC and does not incorporate control schemes into the derived model. Reference [23] has proposed an analytical approach to calculate the dc-side admittance while taking into account several control loops, e.g., the ac-side current control, circulating current control, and the dc-bus voltage control. Alternative methods based on harmonic linearization [17], [18], [24] are also apt since they not only derive the final impedance of the converter, but also provide valuable information on the relationship between the perturbation frequency components of the converter and the control variables. Later, the authors of [25] have developed a linearized dynamic phasor model to calculate the input admittance of the MMC. The study includes a general MMC control scheme including the circulating current control. However, the admittance shaping effect of each of the control loops is not analyzed separately. In addition, the linearization of the model requires the equilibrium point to be obtained beforehand by solving a nonlinear system of equations, or using simulations. Most recently, authors of [26] have calculated the ac- and dc-side admittances of the onshore and the offshore stations for an MMC-based wind farm integrated system considering the relevant control schemes. K. Ji et al. also have developed a small-signal dc impedance model of an MMC using the harmonic transfer function method 
and assessed the harmonic stability of a two-terminal MMCHVDC system [27]. In addition, active damping and utilization of a high-pass filter in the dc voltage control loop have been suggested in the study as measures of improving the harmonic stability of the system. The authors of [28] have proposed a dcside impedance model based on harmonic state-space which considers grid impedance coupling and an outer dc-voltage control loop. In [29], in addition to the dc-side impedance modeling and stability analysis of a multiterminal HVDC system, a thorough investigation has been made into optimizing the controller parameters and adding a virtual damping controller, with a focus on improving the system stability margin. In all of the above literature on dc-side impedance modeling, a direct (open-loop) voltage control approach for the computation of the insertion indices is adopted which provides an asymptotically stable system [30]. With a closedloop voltage control, the ideal insertion indices can be selected provided that an arm-balancing energy or voltage controller is present to stabilize the system. The included arm-balancing controller adds extra nonlinearities to the system which need to be taken into account in the admittance model.

In [19], a method combining harmonic linearization and frequency-domain representation has been developed which analyzes the main perturbation frequency components of the converter variables individually and derives the ac-side admittance model for the MMC accordingly, all while keeping the mathematical complexity of the model at bay. The method illustrates the impact of a generated perturbation component on the converter variables and the effect of the converter parameters on the ac-side admittance of an MMC. Later in [20], the same authors have augmented the study to include different current control schemes in the model while assessing the effect of each control loop on the admittance. Finally, an experimental case study is considered in which the developed admittance model is utilized to assess the stability of the gridconnected system.

Given the above, this paper aims to analytically derive the dc-side admittance of an MMC using the method proposed in [19] while incorporating various control schemes into the study, and considering not only the open-loop, but also the closed-loop scheme of the computation of the insertion indices. To this end, the effect of an added arm-balancing controller and its parameters on the admittance in the closedloop insertion index calculation is investigated. A sufficiently accurate, yet simple dc-side admittance model based on harmonic linearization is derived for both cases which takes into account only five perturbation frequency components and uses an approximated steady-state solution. To assess the validity of the study and determine the accuracy of the developed model, the results are validated using experiments on a down-scaled MMC prototype, and a time-domain simulation model of the same system in MATLAB/SIMULINK.

The paper is organized as follows. Section II describes the time-averaged dynamic model of the MMC and the considered control schemes. Section III explains the theory behind the derivation of the dc-side admittance and discusses the effect of the dynamics of the converter and the control schemes on individual frequency components of the converter and the

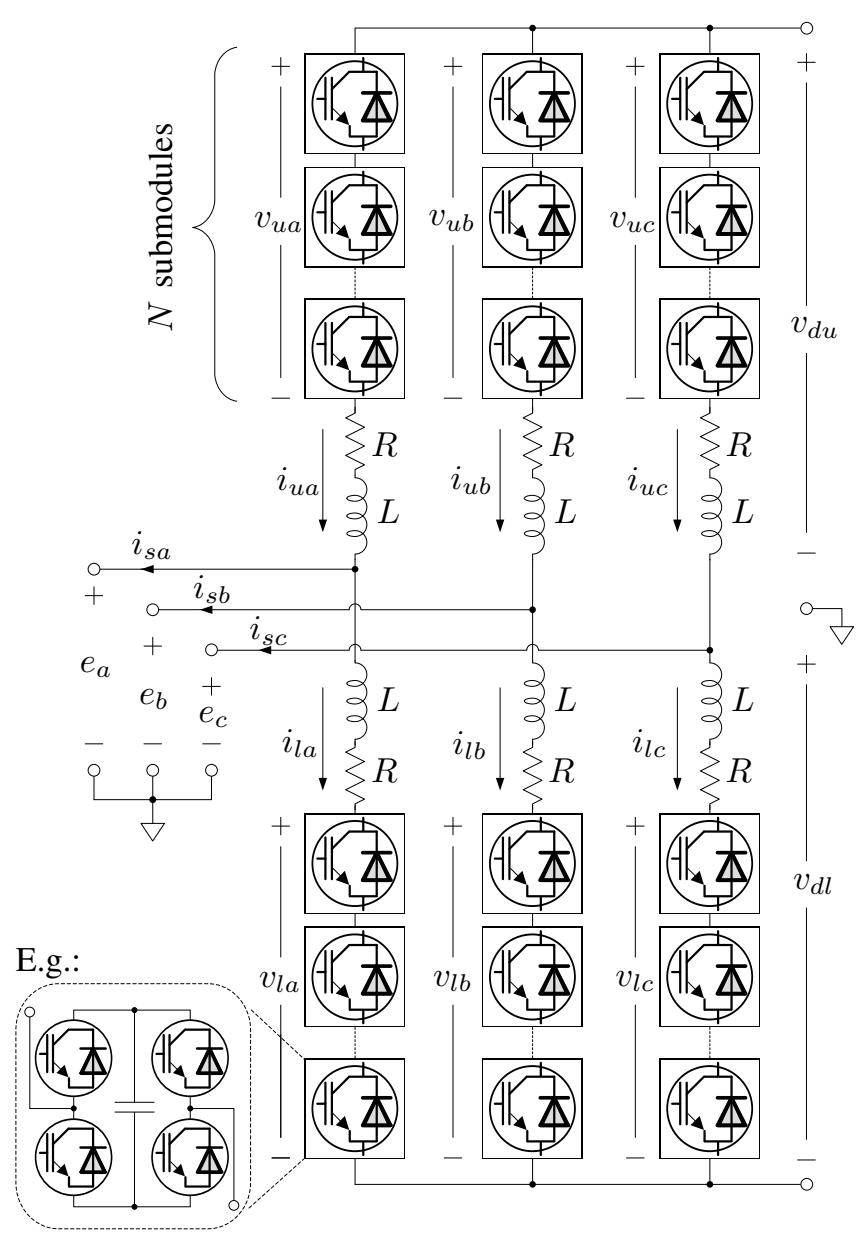

Figure 1. Modular multilevel converter (MMC) topology. A full-bridge submodule configuration is shown as an example.

control variables. Section IV presents and discusses the results of the study. Finally, Section V draws conclusions based on the results.

\section{SySTEM MOdEL}

The MMC used for ac/dc conversion consists of three phases with each phase divided into an upper and a lower arm, see Fig. 1. Each arm comprises $N$ submodules, an arm inductance $L$, and a resistance $R$ which models the losses in the arm. The submodules are usually in half-bridge or full-bridge configurations, but various other topologies also exist [31].

A time-averaged dynamic model for the MMC introduced in [32] is adopted in this study which assumes balanced submodule capacitances within the arm and neglects the switching operations.

\section{A. Dynamics of the Converter}

For the MMC shown in Fig. 1, the dynamics of the armcurrent can be described as

$$
\begin{gathered}
L \frac{\mathrm{d} i_{u}}{\mathrm{~d} t}+R i_{u}=v_{d u}-v_{u}-e \\
L \frac{\mathrm{d} i_{l}}{\mathrm{~d} t}+R i_{l}=v_{d l}-v_{l}+e
\end{gathered}
$$


where $i_{u}\left(i_{l}\right)$ is the upper (lower) arm current, $v_{d u}\left(v_{d l}\right)$ the upper (lower) dc-side voltage, $v_{u}\left(v_{l}\right)$ the upper (lower) arm voltage, and $e$ the voltage of the point of common coupling (PCC) defined as

$$
e=e_{1} \cos [\theta(t)] \quad \text { with } \quad \theta(t)=\omega_{1} t=2 \pi f_{1} t,
$$

with $f_{1}$ as the fundamental frequency.

The dynamics of the arm voltages in the time-averaged model can be described as

$$
v_{u, l}=n_{u, l} v_{C u, l}^{\Sigma},
$$

where $n_{u, l}$ are the (upper and lower arm) insertion indices and $v_{C u, l}^{\Sigma}$ are the (upper and lower arm) sum capacitor voltages.

Assuming balanced capacitor voltages, the expression describing the dynamics of the sum capacitor voltages can be obtained using the relationship between the instantaneous power and the stored energy in the arm [32] as

$$
v_{C u, l}^{\Sigma}=\frac{1}{C} \int n_{u, l} i_{u, l} \mathrm{~d} t+v_{C 0}^{\Sigma},
$$

where $C$ is the arm capacitance and $v_{C 0}^{\Sigma}$ is the initial sum capacitor voltage. The insertion indices $n_{u, l}$ are the outputs of the control system computed by closed-loop feedback control.

Assuming a resistive load $R_{\mathrm{dc}}$ on the dc-side, the dc-side voltage can be defined as

$$
v_{d}=-R_{\mathrm{dc}}\left(i_{u a}+i_{u b}+i_{u c}\right) .
$$

This assumption is based on considerations for the experimental setup and does not impair the validity of the study since the admittance of the converter is not affected by the choice of load.

A phase-locked loop (PLL) is used to estimate the angle of the PCC voltage $\theta$. The angle estimate $\hat{\theta}$ is then used in transforming the phase quantities into the $d q$-frame and in computing the current references.

The following subsection describes the control schemes considered in this paper.

\section{B. Control of the Converter}

The ac-side current $i_{s}$ and the circulating current $i_{c}$ can be defined based on the following transformation of the arm currents [32], [33] as

$$
\begin{aligned}
& i_{s}=i_{u}-i_{l} \\
& i_{c}=\frac{i_{u}+i_{l}}{2} .
\end{aligned}
$$

Using (6) and assuming $v_{d u}=v_{d l}=v_{d} / 2$, (1) can be rewritten as

$$
\begin{aligned}
\frac{L}{2} \frac{\mathrm{d} i_{s}}{\mathrm{~d} t}+\frac{R}{2} i_{s} & =v_{s}-e & \text { with } v_{s} & =\frac{-v_{u}+v_{l}}{2} \\
L \frac{\mathrm{d} i_{c}}{\mathrm{~d} t}+R i_{c} & =\frac{v_{d}}{2}-v_{c} & \text { with } v_{c} & =\frac{v_{u}+v_{l}}{2},
\end{aligned}
$$

where $v_{s}\left(v_{c}\right)$ is the voltage driving $i_{s}\left(i_{c}\right)$. This transformation allows controlling $i_{s}$ and $i_{c}$ independently using two current controllers; one for the ac-side current and the other for the circulating current, see Fig. 2.

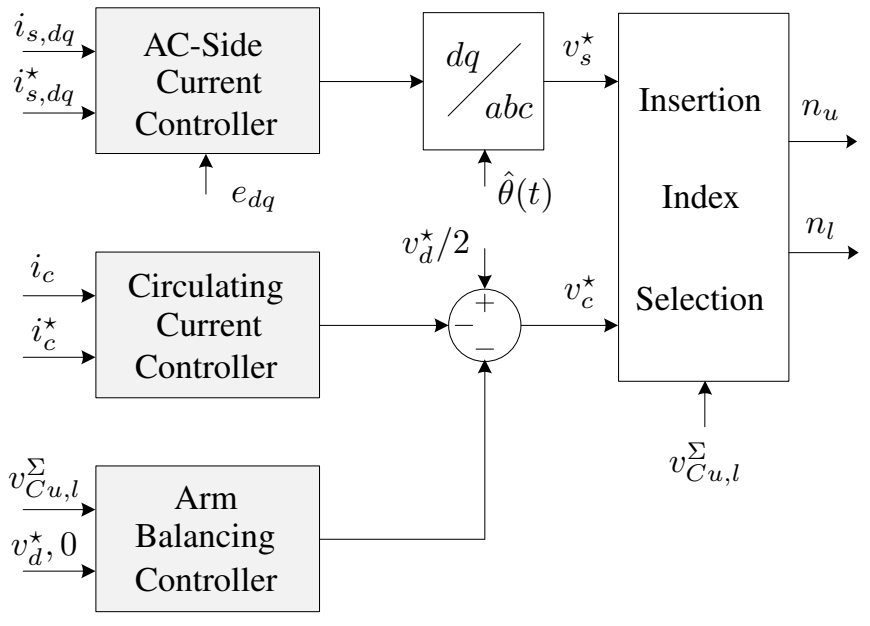

Figure 2. Block diagram of an MMC control scheme with closed-loop voltage control. $d q$-frame ac-side current control, circulating current control, and armbalancing control are applied.

The insertion indices are then computed using the voltage references $v_{s}^{\star}$ and $v_{c}^{\star}$ generated by the current controllers. The ideal insertion indices can be computed based on (3) and (7) as

$$
n_{u}\left(t-T_{d}\right)=\frac{v_{c}^{\star}-v_{s}^{\star}}{v_{C u}^{\Sigma}} \quad n_{l}\left(t-T_{d}\right)=\frac{v_{c}^{\star}+v_{s}^{\star}}{v_{C l}^{\Sigma}},
$$

where $T_{d}$ is the control system delay time, which consists of delays in sampling, digital processing and communication. This provides a closed-loop scheme of the insertion index computation. With the closed-loop approach, the sum capacitor voltages are marginally stable and an arm-balancing controller needs to be implemented to achieve asymptotic stability [34].

Assuming that the arm capacitance $C$ is sufficiently large, the sum capacitor voltage variations $\Delta v_{C u, l}^{\Sigma}$ can be regarded as negligible compared to the dc-bus voltage, i.e., $\Delta v_{C u, l}^{\Sigma} \ll$ $v_{d}$ [32]. Hence, an alternative would be to replace the sum capacitor voltages in (8) with the dc-bus voltage reference $v_{d}^{\star}$, i.e.,

$$
n_{u}\left(t-T_{d}\right)=\frac{v_{c}^{\star}-v_{s}^{\star}}{v_{d}^{\star}} \quad n_{l}\left(t-T_{d}\right)=\frac{v_{c}^{\star}+v_{s}^{\star}}{v_{d}^{\star}} .
$$

The aforementioned open-loop scheme provides inherently asymptotic system stability, meaning that an arm-balancing controller is not required. The disadvantage of the approach is the appearance of harmonic distortions in the arm currents which can be suppressed using resonant current controllers [35].

To assess how control impacts the dc-side admittance of the MMC, the following control schemes are considered in this work and described in the sequel. The aforementioned schemes are adopted from [20] and explained in more detail in [30].

1) dq-Frame AC-Side Current Control: The ac-side current in the synchronous $d q$-frame is controlled via proportional integral (PI) controllers along with feedforward terms of the PCC voltage in the $d q$-frame and relevant current decoupling 
terms. Accordingly, the voltage references $v_{s d}^{\star}$ and $v_{s q}^{\star}$ are given by

$$
\begin{aligned}
& v_{s d}^{\star}=G_{c, d q}(s)\left(i_{s d}^{\star}-i_{s d}\right)+H_{\mathrm{lpf}}(s) e_{d}-\omega_{1} \frac{L}{2} i_{s q} \\
& v_{s q}^{\star}=G_{c, d q}(s)\left(i_{s q}^{\star}-i_{s q}\right)+H_{\mathrm{lpf}}(s) e_{q}+\omega_{1} \frac{L}{2} i_{s d},
\end{aligned}
$$

where $G_{c, d q}(s)$ is a PI controller of the form

$$
G_{c, d q}(s)=\alpha_{s} \frac{L}{2}\left(1+\frac{2 \alpha_{1}}{s}\right),
$$

with $\alpha_{s}$ setting the closed-loop system bandwidth, $\alpha_{1}$ the integral controller gain, and $s$ as the Laplace variable. $H_{\mathrm{lpf}}(s)$ is a low-pass filter with bandwidth $\alpha_{f}$

$$
H_{\mathrm{lpf}}(s)=\frac{\alpha_{f}}{s+\alpha_{f}} .
$$

The references for the $d$ - and $q$-components of the ac-side current can be derived from the power references as

$$
i_{s d}^{\star}=\frac{2 P^{\star}}{3 e_{1}^{\star}} \quad i_{s q}^{\star}=-\frac{2 Q^{\star}}{3 e_{1}^{\star}} .
$$

Thereafter, $v_{s d}^{\star}$ and $v_{s q}^{\star}$ are transformed into the stationary reference frame and used in computation of the insertion indices according to (9).

2) Circulating Current Control: The circulating current controller is of the form

$$
v_{c}^{\star}=\frac{v_{d}^{\star}}{2}-G_{c c}(s)\left(i_{c}^{\star}-i_{c}\right),
$$

where $G_{c c}(s)$, the proportional resonant (PR) controller, is given by

$$
G_{c c}(s)=\alpha_{c} L\left(1+\frac{2 \alpha_{2} s}{s^{2}+\left(2 \omega_{1}\right)^{2}}\right),
$$

with $\alpha_{c}$ setting the closed-loop system bandwidth and $\alpha_{2}$ the resonant controller gain. Neglecting the losses in the arms, the circulating current reference $i_{c}^{\star}$ is computed using the active power reference as

$$
i_{c}^{\star}=\frac{P^{\star}}{3 v_{d}^{\star}} .
$$

3) DC-Bus-Voltage Control: The active power reference can be manipulated to regulate the dc-bus voltage. To this end, we introduce the effective dc-bus energy $W_{d}=6 C v_{d}^{2}$ as the controlled variable. Accordingly, the active power reference is defined as

$$
P^{\star}=F_{\mathrm{dc}}(s)\left(W_{d}^{\star}-W_{d}\right),
$$

where $F_{\mathrm{dc}}(s)$ is a PI controller of the form

$$
F_{\mathrm{dc}}(s)=-\alpha_{d}\left(1+\frac{\alpha_{i d}}{s}\right),
$$

with $\alpha_{d}$ setting the closed-loop system bandwidth and $\alpha_{i d}$ as the integral gain of the controller. Thereafter, the $d$-component of the ac-side current reference is computed by (13) and fed into the current controller.
4) Arm-Balancing Control: The average and the imbalance sum capacitor voltages defined as

$$
v_{C}^{\Sigma}=\frac{v_{C u}^{\Sigma}+v_{C l}^{\Sigma}}{2} \quad v_{C}^{\Delta}=v_{C u}^{\Sigma}-v_{C l}^{\Sigma}
$$

are controlled to $v_{d}^{\star}$ and 0 , respectively. Hence, the reference voltage driving the circulating current is modified to

$v_{c}^{\star}=\frac{v_{d}^{\star}}{2}-G_{c c}(s)\left(i_{c}^{\star}-i_{c}\right)-K_{\Sigma}\left(v_{d}^{\star}-v_{C}^{\Sigma}\right)+K_{\Delta} v_{C}^{\Delta}\left(-\frac{v_{s}^{\star}}{e_{1}^{\star}}\right)$,

where $K_{\Sigma}$ and $K_{\Delta}$ are proportional gains of the controller and $-v_{s}^{\star} / e_{1}^{\star}$ generates a fundamental frequency component in phase with $n_{u}$.

\section{DC-Side Admittance Model}

To calculate the dc-side admittance of the converter, a smallsignal perturbation is superimposed on the dc-side voltage, i.e.,

$$
v_{\mathrm{dc}}(t)=v_{d}(t)+v_{p} \cos \left(\omega_{p} t\right) \quad \text { s.t. } \quad V_{\mathrm{dc}}\left(f_{p}\right) \ll V_{\mathrm{dc}}(0),
$$

where $V_{\mathrm{dc}}(0)$ and $V_{\mathrm{dc}}\left(f_{p}\right)$ denote the dc component and the perturbation frequency component of the Fourier expansion of $v_{\mathrm{dc}}$, respectively, and $v_{d}(t)$ is defined in (5).

The dc-side admittance of the converter can then be calculated as

$$
Y_{\mathrm{dc}}\left(f_{p}\right)=\frac{I_{\mathrm{dc}}\left(f_{p}\right)}{V_{\mathrm{dc}}\left(f_{p}\right)}
$$

i.e., the ratio between the current response to the applied voltage perturbation [36].

The small-signal perturbation superimposed on the dc-side voltage will generate harmonic responses in converter variables, i.e, arm currents, arm voltages, sum capacitor voltages, and by implication, the insertion indices. These harmonic responses appear at a combination of the steady-state and the perturbation frequencies, i.e., $n f_{p}+m f_{1}, n \in \mathbb{N}, m \in \mathbb{Z}$. In theory, an infinite number of harmonic components are produced in the converter and the control variables via the injection of a single perturbation component due to the multiharmonic nature of the system. For best accuracy all of these components need to be considered, however, this is not practical. To keep the complexity at bay, two steadystate values, i.e., 0 and $f_{1}$, and five perturbation values, i.e., $f=\left(f_{p}, f_{p} \pm f_{1}, f_{p} \pm 2 f_{1}\right)$ are considered in this work. These frequencies are combined through addition and subtraction, as seen in Table I, to constitute the frequency components in which the harmonic response of the converter variables are assessed. The expansion to include more components is straightforward and an error analysis between the derived analytical models and a time-domain simulation model of the same system is provided in Section IV. The harmonic linearization technique is used to calculate the harmonic responses using a linear system of equations in an attempt to eventually compute $I_{\mathrm{dc}}\left(f_{p}\right)$ and derive the dc-side admittance of the converter. 
Table I

CONSIDERED FREQUENCY COMPONENTS (HIGHLIGHTED): PERTURBATION (DISTURBANCE) FREQUENCIES (FIRST COLUMN) ARE COMBINED WITH THE STEADY-STATE COMPONENTS (FIRST ROW) THROUGH ADDITION AND SUBTRACTION.

\begin{tabular}{c|c|c|c}
\hline & $-f_{1}$ & 0 & $f_{1}$ \\
\hline$f_{p}-2 f_{1}$ & $f_{p}-3 f_{1}$ & $f_{p}-2 f_{1}$ & $f_{p}-f_{1}$ \\
\hline$f_{p}-f_{1}$ & $f_{p}-2 f_{1}$ & $f_{p}-f_{1}$ & $f_{p}$ \\
\hline$f_{p}$ & $f_{p}-f_{1}$ & $f_{p}$ & $f_{p}+f_{1}$ \\
\hline$f_{p}+f_{1}$ & $f_{p}$ & $f_{p}+f_{1}$ & $f_{p}+2 f_{1}$ \\
\hline$f_{p}+2 f_{1}$ & $f_{p}+f_{1}$ & $f_{p}+2 f_{1}$ & $f_{p}+3 f_{1}$ \\
\hline
\end{tabular}

\section{A. Frequency Domain Analysis of Converter Variables}

The perturbation components of the MMC variables, i.e., $i_{u}, v_{u}, v_{C u}^{\Sigma}$ and $n_{u}$, are obtained in linear form at frequencies highlighted in Table I. The expressions at $f_{p}$ are presented in this subsection, whereas the expressions at $f=\left(0, f_{1}, f_{p} \pm\right.$ $f_{1}, f_{p} \pm 2 f_{1}$ ) are given in the Appendix. Due to inherent symmetries of the MMC topology, the analysis of one of the arms, in this case the upper arm of phase $a$, suffices.

Upper Arm Current: The perturbation component of the upper arm current at $f_{p}$ can be obtained from the frequencydomain representation of the dynamics of the arm current given in (1) as

$$
I_{u}\left(f_{p}\right)=\frac{v_{p} / 4}{j \omega_{p} L+R+\frac{3}{2} R_{\mathrm{dc}}}-\frac{V_{u}\left(f_{p}\right)}{j \omega_{p} L+R+\frac{3}{2} R_{\mathrm{dc}}} .
$$

Note that (23) contains the term $3 / 2 R_{\mathrm{dc}}$, since the zerosequence components of the arm currents flow into the load.

Upper Arm Voltage: The multiplication of the terms in (3) in the time-domain gives rise to combination of the frequency components of $n_{u}$ and $v_{C u}^{\Sigma}$ through addition and subtraction in the frequency-domain. For instance, $f_{p}$ is obtained from $f_{p}+0$, $\left(f_{p}-f_{1}\right)+f_{1}$ and $\left(f_{p}+f_{1}\right)-f_{1}$. The over-line bar denotes the complex conjugate of the Fourier coefficient. Thus, Hermitian symmetry holds $X(-f)=\overline{X(f)}$. Consequently, (3) can be expressed at $f_{p}$ as

$$
\begin{aligned}
V_{u}\left(f_{p}\right)= & V_{C u}^{\Sigma}\left(f_{p}\right) N_{u}(0)+N_{u}\left(f_{p}\right) V_{C u}^{\Sigma}(0) \\
& +V_{C u}^{\Sigma}\left(f_{p}-f_{1}\right) N_{u}\left(f_{1}\right)+N_{u}\left(f_{p}-f_{1}\right) V_{C u}^{\Sigma}\left(f_{1}\right) \\
& +V_{C u}^{\Sigma}\left(f_{p}+f_{1}\right) \overline{N_{u}\left(f_{1}\right)}+N_{u}\left(f_{p}+f_{1}\right) \overline{V_{C u}^{\Sigma}\left(f_{1}\right)} .
\end{aligned}
$$

The steady-state components of $n_{u}$ and $v_{C u}^{\Sigma}$ are computed beforehand (see Appendix), thus rendering (24), (59)-(62) linear.

Upper Arm Sum Capacitor Voltage: The same reasoning as for (24) applies here, where the multiplication of $n_{u}$ and $i_{u}$ in (4) leads to combinations of the frequency spectra of these variables through addition and subtraction, i.e.,

$$
\begin{aligned}
V_{C u}^{\Sigma}\left(f_{p}\right)= & \frac{1}{j \omega_{p} C}\left[I_{u}\left(f_{p}\right) N_{u}(0)+N_{u}\left(f_{p}\right) I_{u}(0)\right. \\
& +I_{u}\left(f_{p}-f_{1}\right) N_{u}\left(f_{1}\right)+N_{u}\left(f_{p}-f_{1}\right) I_{u}\left(f_{1}\right) \\
& \left.+I_{u}\left(f_{p}+f_{1}\right) \overline{N_{u}\left(f_{1}\right)}+N_{u}\left(f_{p}+f_{1}\right) \overline{I_{u}\left(f_{1}\right)}\right] .
\end{aligned}
$$

Upper Arm Insertion Index: The frequency domain analysis of the open-loop scheme of computing insertion indices according to (9) results in

$$
N_{u}(f)=\frac{V_{c}^{\star}(f)-V_{s}^{\star}(f)}{v_{d}^{\star}} e^{-j 2 \pi f T_{d}},
$$

for $f=\left(f_{p}, f_{p} \pm f_{1}, f_{p} \pm 2 f_{1}\right)$. Note that the controller system delay time $T_{d}$ appears as an exponential term in the frequencydomain.

For the closed-loop scheme of insertion index computation, (26) is modified to

$$
N_{u}(f)=\frac{V_{c}^{\star}(f)-V_{s}^{\star}(f)}{V_{C u}^{\Sigma}(f)} e^{-j 2 \pi f T_{d}},
$$

which introduces nonlinearities to the calculations as $V_{C u}^{\Sigma}$ is a function of $N_{u}$ and $I_{u}$ through (25) and (55)-(58), and not a constant. Hence, to analytically calculate the admittance with this control approach, (27) must be linearized.

\section{B. Frequency Domain Analysis of the Control Variables}

The perturbation components of the control variables, i.e., $V_{s}^{\star}$ and $V_{c}^{\star}$ are derived in linear form.

1) dq-Frame AC-Side Current Control: The $a b c / d q$ transformation projects the frequency components in the phases at $f_{p} \pm f_{1}$ to $f_{p}$. This implies that the only perturbation frequency component in the $d q$-frame is at $f_{p}$. Therefore, the $d$ - and the $q$-components of the output voltage are obtained as

$$
\begin{aligned}
V_{s d}^{\star}\left(f_{p}\right) & =-G_{c, d q}\left(j \omega_{p}\right) I_{s d}\left(f_{p}\right)-\frac{\omega_{1} L}{2} I_{s q}\left(f_{p}\right) \\
V_{s q}^{\star}\left(f_{p}\right) & =-G_{c, d q}\left(j \omega_{p}\right) I_{s q}\left(f_{p}\right)+\frac{\omega_{1} L}{2} I_{s d}\left(f_{p}\right) .
\end{aligned}
$$

The respective components of the output current can be obtained by the $d q$ transformation

$$
i_{s d}=i_{s \alpha} a+i_{s \beta} b \quad i_{s q}=-i_{s \alpha} b+i_{s \beta} a,
$$

where $a=\cos [\hat{\theta}(t)]$ and $b=\sin [\hat{\theta}(t)]$. The perturbation frequency components of $i_{s \alpha}$ and $i_{s \beta}$ are at $f_{p} \pm f_{1}$. This implies that the perturbation frequency component of $i_{s}$ in the $d q$-frame is at $f_{p}$. To this end, the aforementioned variables are defined as

$$
\begin{aligned}
I_{s d}\left(f_{p}\right)= & I_{s \alpha}\left(f_{p}-f_{1}\right) A\left(f_{1}\right)+I_{s \beta}\left(f_{p}-f_{1}\right) B\left(f_{1}\right) \\
& +I_{s \alpha}\left(f_{p}+f_{1}\right) \overline{A\left(f_{1}\right)}+I_{s \beta}\left(f_{p}+f_{1}\right) \overline{B\left(f_{1}\right)} \\
I_{s q}\left(f_{p}\right)= & -I_{s \alpha}\left(f_{p}-f_{1}\right) B\left(f_{1}\right)+I_{s \beta}\left(f_{p}-f_{1}\right) A\left(f_{1}\right) \\
& -I_{s \alpha}\left(f_{p}+f_{1}\right) \overline{B\left(f_{1}\right)}+I_{s \beta}\left(f_{p}+f_{1}\right) \overline{A\left(f_{1}\right)},
\end{aligned}
$$

where $A\left(f_{1}\right)=1 / 2$ and $B\left(f_{1}\right)=1 / 2 j$.

With $I_{s \alpha}(f)=I_{s}(f)$ for $f=f_{p} \pm f_{1}, I_{s \beta}\left(f_{p}-f_{1}\right)=$ $j I_{s}\left(f_{p}-f_{1}\right)$ and $I_{s \beta}\left(f_{p}+f_{1}\right)=-j I_{s}\left(f_{p}+f_{1}\right)$, (30) can be simplified to

$$
\begin{aligned}
& I_{s d}\left(f_{p}\right)=I_{s}\left(f_{p}-f_{1}\right)+I_{s}\left(f_{p}+f_{1}\right) \\
& I_{s q}\left(f_{p}\right)=j I_{s}\left(f_{p}-f_{1}\right)-j I_{s}\left(f_{p}+f_{1}\right) .
\end{aligned}
$$


Similarly, the voltage references in the $d q$-frame are transformed to the $\alpha \beta$-frame

$$
v_{s \alpha}^{\star}=v_{s d}^{\star} a-v_{s q}^{\star} b \quad v_{s \beta}^{\star}=v_{s d}^{\star} b+v_{s q}^{\star} a,
$$

and used to derive the frequency components of $v_{s}^{\star}$ as

$$
\begin{aligned}
V_{s}^{\star}\left(f_{p}-f_{1}\right) & =\frac{1}{2} V_{s d}^{\star}\left(f_{p}\right)-\frac{j}{2} V_{s q}^{\star}\left(f_{p}\right) \\
V_{s}^{\star}\left(f_{p}+f_{1}\right) & =\frac{1}{2} V_{s d}^{\star}\left(f_{p}\right)+\frac{j}{2} V_{s q}^{\star}\left(f_{p}\right) .
\end{aligned}
$$

2) Circulating Current Control: Components at $f_{p}$ and $f_{p} \pm 2 f_{1}$ appear in the circulating current. Thus, (14) can be represented in the frequency domain at the aforementioned frequencies as

$$
\begin{aligned}
V_{c}^{\star}\left(f_{p}\right) & =G_{c c}\left[j\left(\omega_{p}\right)\right] I_{c}\left(f_{p}\right) \\
V_{c}^{\star}\left(f_{p} \pm 2 f_{1}\right) & =G_{c c}\left[j\left(\omega_{p} \pm 2 \omega_{1}\right)\right] I_{c}\left(f_{p} \pm 2 f_{1}\right),
\end{aligned}
$$

where $I_{c}(f)=I_{u}(f)$ for $f=\left(f_{p}, f_{p} \pm 2 f_{1}\right)$.

3) DC-Bus-Voltage Control: The $d$-component of the acside current reference is manipulated through changes in the active power reference. Therefore, $I_{s d}^{\star}$ includes a perturbation component at $f_{p}$. The perturbation frequency component of $V_{s d}^{\star}$ is defined accordingly as

$$
V_{s d}^{\star}\left(f_{p}\right)=G_{c, d q}\left(j \omega_{p}\right)\left(I_{s d}^{\star}\left(f_{p}\right)-I_{s d}\left(f_{p}\right)\right)-\frac{\omega_{1} L}{2} I_{s q}\left(f_{p}\right),
$$

where $I_{s d}^{\star}\left(f_{p}\right)$ is calculated by linearizing (17) as

$$
P^{\star}=6 C F_{\mathrm{dc}}(s) \times 2 v_{d}^{\star}\left(v_{d}^{\star}-v_{d}\right),
$$

and then substituting (36) in (13) and expressing it in frequency domain at $f_{p}$ as

$$
I_{s d}^{\star}\left(f_{p}\right)=\frac{2 P^{\star}}{3 e_{1}^{\star}}=-8 C \frac{v_{d}^{\star}}{e_{1}^{\star}} F_{\mathrm{dc}}(s) V_{\mathrm{dc}}\left(f_{p}\right),
$$

where $V_{\mathrm{dc}}\left(f_{p}\right)=-3 R_{\mathrm{dc}} I_{u}\left(f_{p}\right)+v_{p} / 2$.

4) Arm-Balancing Control: The controller modifies the voltage reference $v_{c}^{\star}$. Components at $f=\left(f_{p}, f_{p} \pm f_{1}, f_{p} \pm 2 f_{1}\right)$ appear in $V_{c}^{\star}$ due to the symmetry of the MMC topology. Evaluating (20) at $f_{p}$, e.g., results in

$$
\begin{aligned}
V_{c}^{\star}\left(f_{p}\right) & =G_{c c}\left(j \omega_{p}\right) I_{c}\left(f_{p}\right)+K_{\Sigma} v_{C u}^{\Sigma}\left(f_{p}\right) \\
& -\frac{K_{\Delta}}{e_{1}^{\star}}\left(v_{C}^{\Delta}\left(f_{p}-f_{1}\right) V_{s}^{\star}\left(f_{1}\right)+v_{C}^{\Delta}\left(f_{p}+f_{1}\right) \overline{V_{s}^{\star}\left(f_{1}\right)}\right),
\end{aligned}
$$

where $V_{s}^{\star}\left(f_{1}\right) \approx e_{1}^{\star} / 2$. Knowing $V_{C u}^{\Sigma}\left(f_{p} \pm f_{1}\right)=-V_{C l}^{\Sigma}\left(f_{p} \pm\right.$ $f_{1}$ ), and considering (19), (38) can be approximated as

$$
\begin{aligned}
V_{c}^{\star}\left(f_{p}\right) & =G_{c c}\left(j \omega_{p}\right) I_{c}\left(f_{p}\right)+K_{\Sigma} v_{C u}^{\Sigma}\left(f_{p}\right) \\
& -K_{\Delta}\left(v_{C u}^{\Sigma}\left(f_{p}-f_{1}\right)+v_{C u}^{\Sigma}\left(f_{p}+f_{1}\right)\right) .
\end{aligned}
$$

The remaining perturbation frequency components of $v_{c}^{\star}$, i.e., $V_{c}^{\star}\left(f_{p} \pm f_{1}\right)$ and $V_{c}^{\star}\left(f_{p} \pm 2 f_{1}\right)$ can be calculated in a similar fashion.

\section{Closed-Loop Computation of the Insertion Indices}

The closed-loop scheme produces a $v_{c}$ and $v_{s}$ that replicate their references, i.e.,

$$
v_{c}=v_{c}^{\star} e^{-s T_{d}} \quad v_{s}=v_{s}^{\star} e^{-s T_{d}} .
$$

It has been shown in [20] that the utilization of the closedloop computation of the insertion indices decouples the ac- and the dc-sides of the converter. This implies that no perturbation frequency components exist in $V_{s}^{\star}$, i.e., $V_{s}^{\star}(f)=0$ for $f=\left(f_{p}, f_{p} \pm f_{1}, f_{p} \pm 2 f_{1}\right)$. Nevertheless, owing to the necessity of an arm-balancing controller to ensure the system stability in this scheme, $v_{c}^{\star}$ is now a function of the sum capacitor voltages through (20). Therefore, the circulating current controller and the arm-balancing controller both influence the dc-side admittance of the converter. In addition, the division by $v_{C u, l}^{\Sigma}$ in (8) results in the appearance of nonlinear terms in $n_{u}$. To resolve the latter, the division in (8) is linearized as

$$
\frac{1}{v_{C u}^{\Sigma}}=\frac{2}{v_{C 0}^{\Sigma}}-\frac{v_{C u}^{\Sigma}}{\left(v_{C 0}^{\Sigma}\right)^{2}} .
$$

Subsequently, the nonlinear terms produced through multiplication of $v_{C u}^{\Sigma}$ terms in (8) with $v_{c}^{\star}$ are linearized to include the dynamics resulting from the employed arm-balancing controller. A minimum number of frequency components of the converter variables are chosen as seen in Table I to ensure the simplicity of the model.

As an example, the perturbation frequency component of $n_{u}$ at $f_{p}$ can be calculated as

$$
\begin{aligned}
& N_{u}\left(f_{p}\right)=e^{-j \omega_{p} T_{d}}\left[\frac{G_{c c}\left(j \omega_{p}\right)}{v_{C 0}^{\Sigma}} I_{u}\left(f_{p}\right)\right. \\
& +\left(\frac{K_{\Sigma}}{v_{C 0}^{\Sigma}}-\frac{V_{u}^{\star}(0)}{\left(v_{C 0}^{\Sigma}\right)^{2}}\right) V_{C u}^{\Sigma}\left(f_{p}\right) \\
& -\left(\frac{K_{\Delta}}{v_{C 0}^{\Sigma}}-\frac{V_{u}^{\star}\left(f_{1}\right)}{\left(v_{C 0}^{\Sigma}\right)^{2}}\right) V_{C u}^{\Sigma}\left(f_{p}-f_{1}\right) \\
& \left.-\left(\frac{K_{\Delta}}{v_{C 0}^{\Sigma}}-\frac{\overline{V_{u}^{\star}\left(f_{1}\right)}}{\left(v_{C 0}^{\Sigma}\right)^{2}}\right) V_{C u}^{\Sigma}\left(f_{p}+f_{1}\right)\right] .
\end{aligned}
$$

The remaining perturbation frequency components of $n_{u}$ are given in the Appendix.

\section{Derivation of the Admittance}

A linear system of equations

$$
A_{p} \mathbf{x}_{p}=B_{p}
$$

is built based on expressions describing the perturbation frequency components of the converter and the control variables introduced in Subsections III-A and III-B, where the system variables are chosen as

$$
\begin{aligned}
\mathbf{x}_{p}=[ & I_{u}\left(f_{p}\right), I_{u}\left(f_{p}-f_{1}\right), I_{u}\left(f_{p}+f_{1}\right), I_{u}\left(f_{p}-2 f_{1}\right) \\
& I_{u}\left(f_{p}+2 f_{1}\right), V_{u}\left(f_{p}\right), V_{u}\left(f_{p}-f_{1}\right), V_{u}\left(f_{p}+f_{1}\right) \\
& V_{u}\left(f_{p}-2 f_{1}\right), V_{u}\left(f_{p}+2 f_{1}\right), V_{C u}^{\Sigma}\left(f_{p}\right), V_{C u}^{\Sigma}\left(f_{p}-f_{1}\right) \\
& V_{C u}^{\Sigma}\left(f_{p}+f_{1}\right), V_{C u}^{\Sigma}\left(f_{p}-2 f_{1}\right), V_{C u}^{\Sigma}\left(f_{p}+2 f_{1}\right) \\
& N_{u}\left(f_{p}\right), N_{u}\left(f_{p}-f_{1}\right), N_{u}\left(f_{p}+f_{1}\right), N_{u}\left(f_{p}-2 f_{1}\right) \\
& \left.N_{u}\left(f_{p}+2 f_{1}\right), I_{s d}\left(f_{p}\right), I_{s q}\left(f_{p}\right), V_{s d}^{\star}\left(f_{p}\right), V_{s q}^{\star}\left(f_{p}\right)\right]^{T},
\end{aligned}
$$


with $A_{p}$ and $B_{p}$ containing the coefficient and constant terms in the aforementioned equations, respectively. Solving the linear system (43) yields $\mathbf{x}_{p}=A_{p}^{-1} B_{p}$. Since the MMC topology is symmetrical, it can be assumed that $I_{\mathrm{dc}}\left(f_{p}\right)=$ $3 I_{c}\left(f_{p}\right)=3 I_{u}\left(f_{p}\right)$. Thus, the dc-side admittance of the converter can be determined by

$$
Y_{\mathrm{dc}}\left(f_{p}\right)=\frac{3 I_{u}\left(f_{p}\right)}{V_{\mathrm{dc}}\left(f_{p}\right)}=\frac{3 I_{u}\left(f_{p}\right)}{-3 R_{\mathrm{dc}} I_{u}\left(f_{p}\right)+\frac{v_{p}}{2}} .
$$

1) Simplified Transfer Function: A simplified expression for the dc-side admittance can be given by neglecting the dynamics of the arm-balancing and the ac-side current controllers and substituting (14) in (7b) while assuming $v_{c}^{\star}=v_{c} e^{s T_{d}}$. This results in

$$
\widetilde{Y_{\mathrm{dc}}}=\frac{3 I_{\mathrm{c}}\left(j \omega_{p}\right)}{V_{\mathrm{dc}}\left(j \omega_{p}\right)}=\frac{3}{2\left(j L \omega_{p}+R+G_{c c}\left(j \omega_{p}\right) e^{-j \omega_{p} T_{d}}\right)} .
$$

The above expression is not valid for the entire frequency range, nevertheless, it provides an approximated admittance solution beyond the bandwidth of the ac-side current controller. It can be concluded from (46), that the control system time delay affects the admittance only when $\omega_{p} T_{d}$ grows very large. $G_{c c}(s)$ is a PR controller with proportional gain $\alpha_{c} L$ in frequencies beyond its resonance frequencies (in this case $100 \mathrm{~Hz})$. For $\alpha_{c}<\omega_{d}=\pi /\left(10 T_{d}\right)<\omega_{p}$, the term $j L \omega_{p}$ is the most dominant in the denominator of (46). Thus, it can be concluded that for these frequencies, the admittance seen from the dc-side can be approximated by the parallel connection of the arm $R L$ branches.

\section{RESULTS AND DISCUSSION}

The analytical model developed in Section III is validated through experiments on a down-scaled MMC prototype to demonstrate the effect of different control schemes on the dcside admittance of the converter. The results are also verified against a time-domain MATLAB/SIMULINK model of the same system.

The MMC prototype seen in Fig. 3, has five submodules per arm (30 in total) and is rated for $10 \mathrm{~kW}$ [37]. The control system of the converter is implemented on a Xilinx Zynq7000 system-on-chip which integrates a programmable logic with a processing system. With phase-shifted carrier pulsewidth modulation (PSC-PWM), individual capacitor voltage balancing and symmetrical operation between the arms are ensured, provided that the carrier frequency is a non-integer multiple of the fundamental frequency [38].

The configuration of the experimental setup to measure the dc-side admittance of the MMC is shown in Fig. 4. A single-phase full-bridge programmable inverter which generates a small-signal perturbation is connected in series with the resistive load. Fig. 5 shows the waveforms of the converter variables when a perturbation frequency of $10 \mathrm{~Hz}$ is applied. The amplitude of the perturbation is increased to $4 \mathrm{~V}$ so that the effect on the converter variables is more pronounced. The base voltage is chosen as equal to the PCC voltage amplitude and the base current is computed according to $S_{b}=1.5 V_{b} I_{b}$ where $S_{b}$ is the apparent power reference.

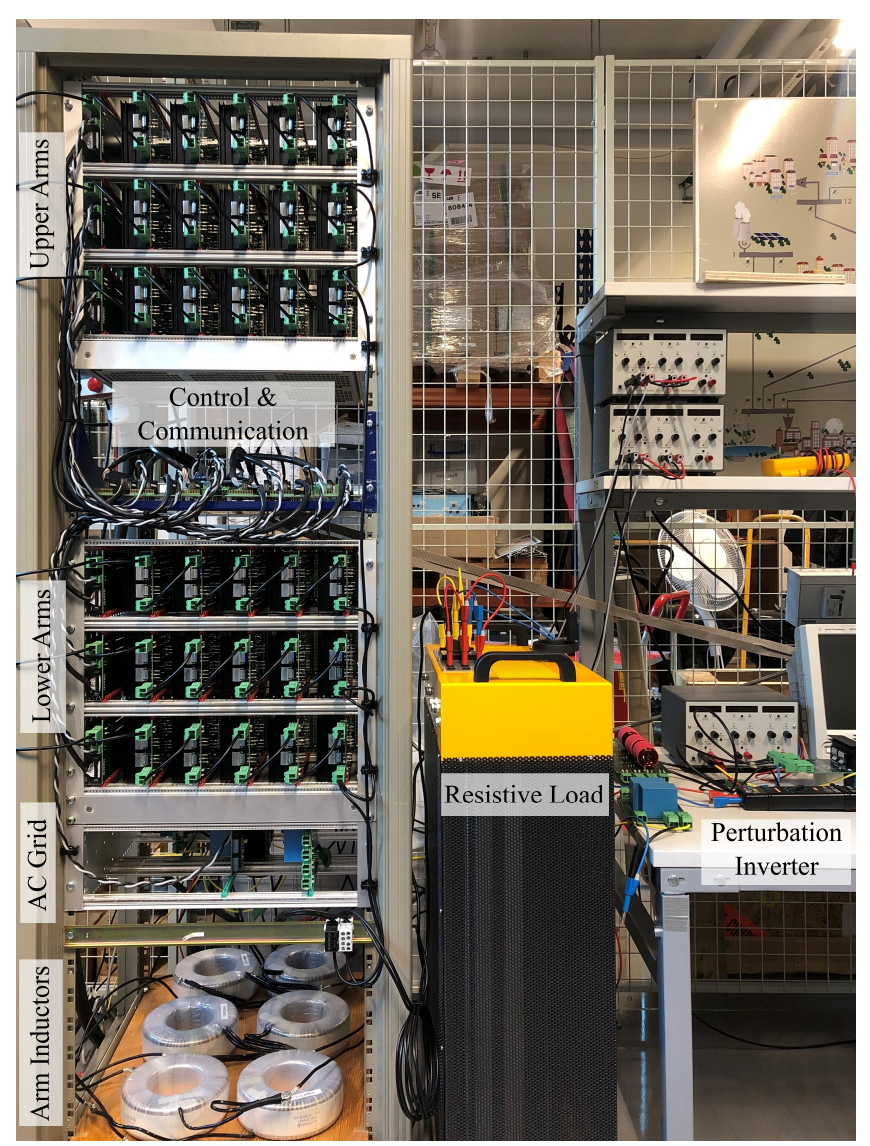

Figure 3. The experimental setup.

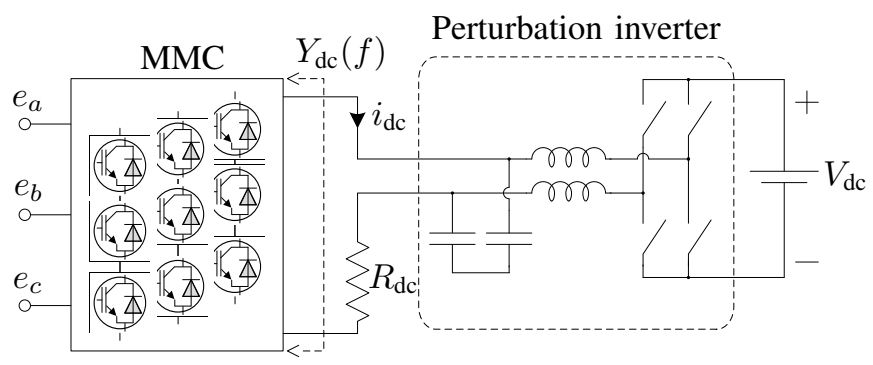

Figure 4. Layout of the experimental setup.

\section{A. Effects of Control on the Admittance}

The parameters of the system and the settings of the controllers are summarized in Tables II and III. For these settings, Bode diagrams of the MMC dc-side admittance using the open-loop scheme of insertion index computation are shown in Fig. 6. The admittance is affected mainly by the choice of the control scheme and the settings of the controllers, e.g., $\alpha_{s}, \alpha_{c}$ and $\alpha_{1}$. The effect of each element of the controllers is observed as they are added sequentially, starting with only the proportional part of the ac-side current control (purple) until the $d q$-frame ac-side current PI controller along with circulating current PR control (red) are implemented. The following observations are made based on the results:

- in all cases, the analytical model (solid lines) matches the measurements (dots), thus confirming the validity of the analytical model derived in Section III; 

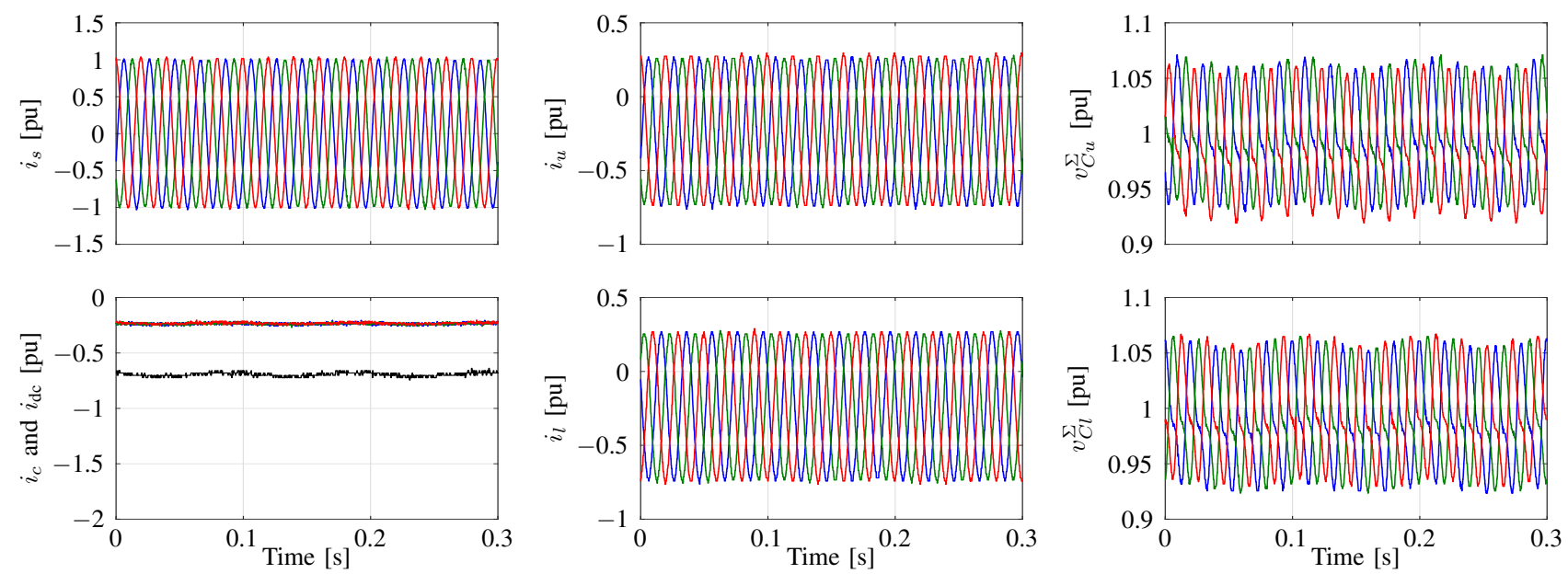

Figure 5. Waveforms of the converter variables during an experiment with $f_{p}=10 \mathrm{~Hz}$; three-phase ac-side current (top-left); dc-side current and threephase circulating currents (bottom-left); three-phase upper and lower arm currents (middle); three-phase upper and lower arm sum capacitor voltages (right). Three-phase waveforms are shown with blue (phase $a$ ), red (phase $b$ ), and green (phase $c$ ).

Table II

PARAMETERS OF THE EXPERIMENTAL SETUP

\begin{tabular}{l|c|l}
\hline \hline PCC voltage amplitude & $e_{1}$ & $24 \mathrm{~V}$ \\
Fundamental frequency & $f_{1}$ & $50 \mathrm{~Hz}$ \\
Resistive load & $R_{\mathrm{dc}}$ & $50 \Omega$ \\
Arm inductance & $L$ & $3.3 \mathrm{mH}$ \\
Arm resistance & $R$ & $0.55 \Omega$ \\
Arm capacitance & $C$ & $0.54 \mathrm{mF}$ \\
Perturbation amplitude & $v_{p}$ & $2 \mathrm{~V}$ \\
Perturbation frequency & $f_{p}$ & $1.67 \mathrm{~Hz}-1 \mathrm{kHz}$ \\
\hline \hline
\end{tabular}

Table III

CONTROLLER PARAMETERS

\begin{tabular}{l|l|l}
\hline \hline Carrier frequency & $f_{c}$ & $763 \mathrm{~Hz}$ \\
Control system delay time & $T_{d}$ & $65.5 \mu \mathrm{s}$ \\
Dc-bus voltage reference & $v_{d}^{\star}$ & $48 \mathrm{~V}$ \\
Active power reference & $P^{\star}$ & $-46 \mathrm{~W}$ \\
Reactive power reference & $Q^{\star}$ & $0 \mathrm{VAr}$ \\
AC-side current closed-loop system bandwidth & $\alpha_{s}$ & $1200 \mathrm{rad} / \mathrm{s}$ \\
AC-side current integral gain & $\alpha_{1}$ & $100 \mathrm{rad} / \mathrm{s}$ \\
PCC voltage feedforward filter bandwidth & $\alpha_{f}$ & $1000 \mathrm{rad} / \mathrm{s}$ \\
Circulating current closed-loop system bandwidth & $\alpha_{c}$ & $500 \mathrm{rad} / \mathrm{s}$ \\
Circulating current resonant controller gain & $\alpha_{2}$ & $100 \mathrm{rad} / \mathrm{s}$ \\
Dc-bus voltage closed-loop system bandwidth & $\alpha_{d}$ & $20-60 \mathrm{rad} / \mathrm{s}$ \\
Dc-bus voltage integral controller gain & $\alpha_{i d}$ & $25 \mathrm{rad} / \mathrm{s}$ \\
Arm-balancing controller average gain & $K_{\Sigma}$ & 2 \\
Arm-balancing controller imbalance gain & $K_{\Delta}$ & 1 \\
\hline \hline
\end{tabular}

- at high frequencies beyond the bandwidth of the controllers, the arm inductances have integral action whereas the controllers have only proportional action. Therefore, the admittance shape at these frequencies is dominated by the arm inductance;

- the addition of circulating current control (yellow and brown), lowers the admittance peaks around the fundamental and double fundamental frequencies;

- the resonant part of the circulating current controller is designed such that it suppresses the $100 \mathrm{~Hz}$ component in the circulating current. Thus, the dc-side admittance of the MMC contains a resonant valley and phase rotation from -90 to 90 degrees at $100 \mathrm{~Hz}$;

- the addition of the integral part of the ac-side current controller (red) significantly reduces the admittance magnitude and increases the phase angle in low (below $20 \mathrm{~Hz}$ ) frequencies. The addition of the integral term provides better harmonic damping, hence further reducing the amplitude of the components appearing in the perturbation frequencies and consequently lowers the admittance in the low frequency band;

- the proportional term of the circulating current controller has a more distinct effect on the admittance shape in below fundamental frequencies and the addition of the resonant term of the circulating current controller does not impact the admittance at these frequencies.

Finally, the dc-bus voltage is controlled through regulating the effective dc-bus energy, as explained in Section II-B. Fig. 7 shows the effect of the dc-bus voltage controller and its proportional gain on the dc-side admittance of the converter. As seen in the figure, the dc-bus voltage controller strongly affects the admittance magnitude and phase at low frequencies, with a greater proportional gain corresponding to a greater admittance magnitude at dc which implies that the system stability has decreased. A low frequency perturbation applied to the dc-side induces a low frequency power (or energy) which needs to be buffered in the ac network or the converter arms. In presence of a dc-bus voltage controller, a greater portion of this energy is buffered in the ac network rather than the arms. The energy controlled in the arms, thus lowers the amplitude of the perturbation frequency component of the dcside voltage and increases the dc-side admittance. It has been shown in [27] that the inclusion of a high-pass filter within the dc-bus voltage controller can help mitigate this adverse effect.

The stability margin of the grid-connected converter is improved with lower admittance magnitude and limited phase rotation [20]. Thus, the following conclusions can be drawn from the observations made above:

- the ac-side current integral control is beneficial in that it lowers the admittance magnitude while increasing the 
phase angle in frequencies below the fundamental;

- the circulating current controller has great impact on the converter admittance seen from the dc-side, similar to its effect on the ac-side impedance of the MMC [39];

- the outer control loops, e.g., a dc-bus voltage controller, have considerable effect on the admittance magnitude in low frequencies and the system stability.
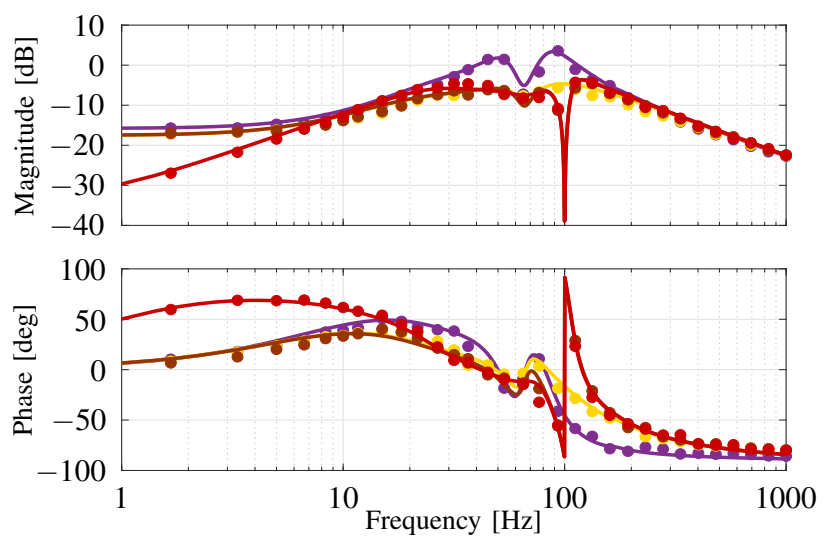

Figure 6. Bode diagram of the MMC dc-side admittance for different control schemes: $d q$-frame ac-side current proportional controller (purple); addition of circulating current proportional controller (yellow); addition of circulating current resonant controller (brown); addition of ac-side current integral controller (red). The analytical models are indicated by the solid lines and the measurements with dots.

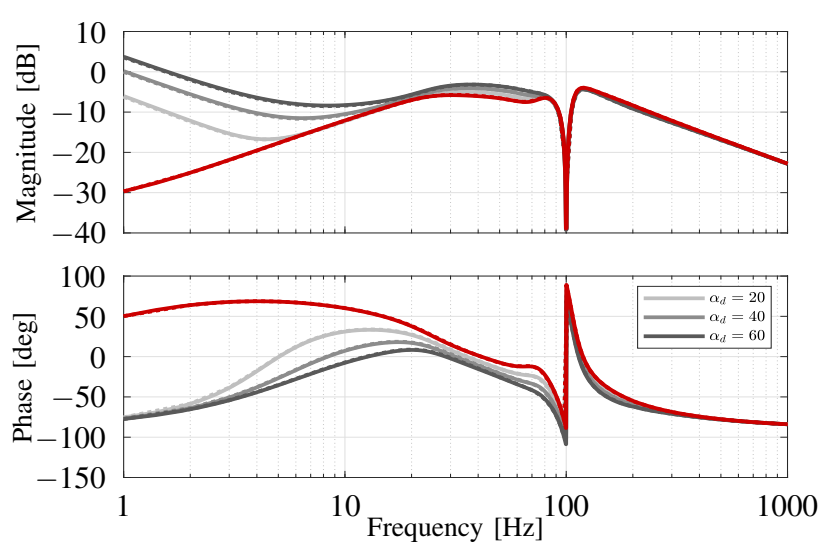

Figure 7. Bode diagram of the MMC dc-side admittance for different control schemes: $d q$-frame ac-side current control and circulating current control (red); addition of dc-bus voltage control with different proportional gains (light gray to dark gray). The unit for the gains is $\mathrm{rad} / \mathrm{s}$. The analytical models are shown by solid lines and the results obtained through time-domain simulations are shown by dotted lines.

\section{B. Effect of Control System Time Delay}

The effect of the control system time delay $T_{d}$ on the dc-side admittance is discussed in this subsection. To this end, the presented analytical model is utilized in deriving the admittance of the converter. Fig. 8 shows the Bode plots of the dc-side admittance of the MMC with $d q$-frame ac-side and
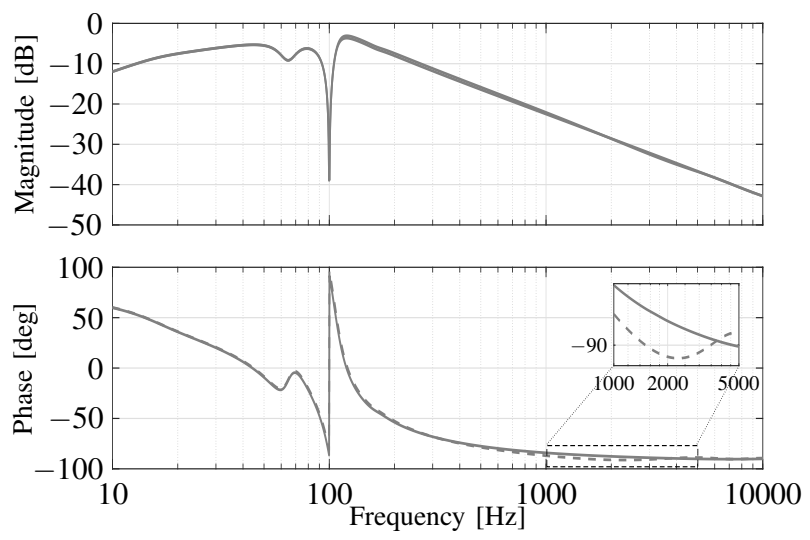

Figure 8. Bode diagram of the MMC dc-side admittance for different control system time delay values; $T_{d}=65.5 \mu \mathrm{s}$ (solid) and $T_{d}=200 \mu \mathrm{s}$ (dashed). The ac-side current and circulating current are controlled. Only the analytical model is shown. A close-up between $1 \mathrm{kHz}$ and $5 \mathrm{kHz}$ is provided within the phase angle plot.

circulating current control for different values of $T_{d}$. As seen in the figure, the control system time delay has negligible effect on the magnitude of the admittance, but affects the phase in the high-frequency region. For instance, with a $200 \mu$ s time delay, the phase drops below -90 degrees at approximately $2000 \mathrm{~Hz}$, implying non-passivity of $Y_{\mathrm{dc}}(s)$ which may indicate closedloop system instability [11], [40].

\section{Effect of the Closed-Loop Scheme}

Bode diagrams of the dc-side admittance of the MMC with both types of insertion index computation, i.e., open-loop and closed-loop scheme, are shown in Fig. 9. The analytical model derived for the closed-loop scheme (blue line) matches the experimental results (blue dots), confirming the validity of the model in spite of the approximations made when linearizing the equations describing the system. Significant differences can be observed in the dc-side admittance of the converter when using the open-loop or the closed-loop schemes. An additional phase rotation is introduced in the admittance Bode plot in the closed-loop scheme due to the presence of the armbalancing controller. In the considered operating point with the controller settings introduced in Table III, the admittance magnitude is lower with the closed-loop scheme than that of the open-loop scheme in nearly the whole frequency range within the bandwidth of the controllers.

The error between the presented analytical models which take into account a finite number of perturbation and steadystate frequency components, and time-domain simulations in MATLAB/SIMULINK which consider all harmonics is given in Fig. 10, to provide an overview of the model accuracy. With the open-loop scheme of insertion index calculation, the error is quite low. Due to linearizations and simplifications made in (39) and (41), the error of the analytical model of the closed-loop scheme has grown larger compared to that of the open-loop scheme, especially around the resonant peak introduced by the arm-balancing controller. Nevertheless, the closed-loop model calculates the admittance with relatively 

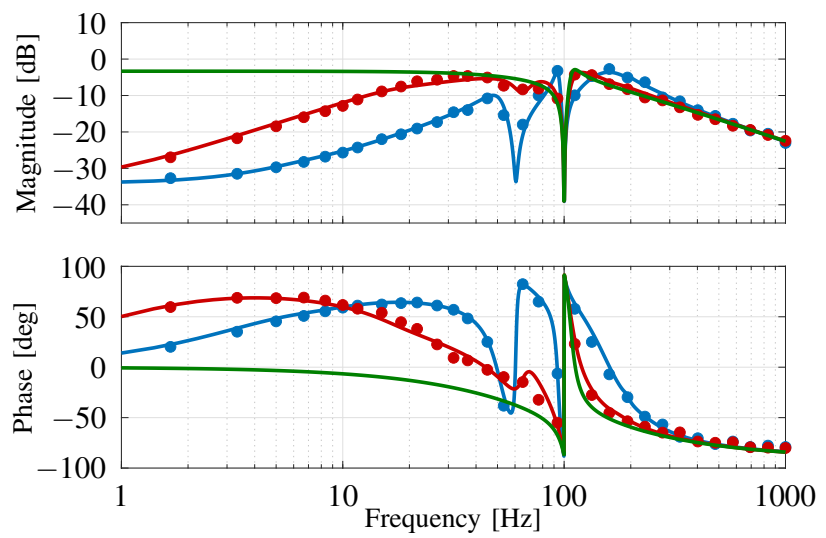

Figure 9. Bode diagram of the MMC dc-side admittance for different types of insertion index computation: open-loop scheme (red) and closed-loop scheme (blue), simplified model based on (46) (green). The converter is operated with $d q$-frame ac-side current control and circulating current control. In the closedloop scheme, an arm-balancing controller is also implemented. The analytical models are indicated by the solid lines and the measurements with dots.

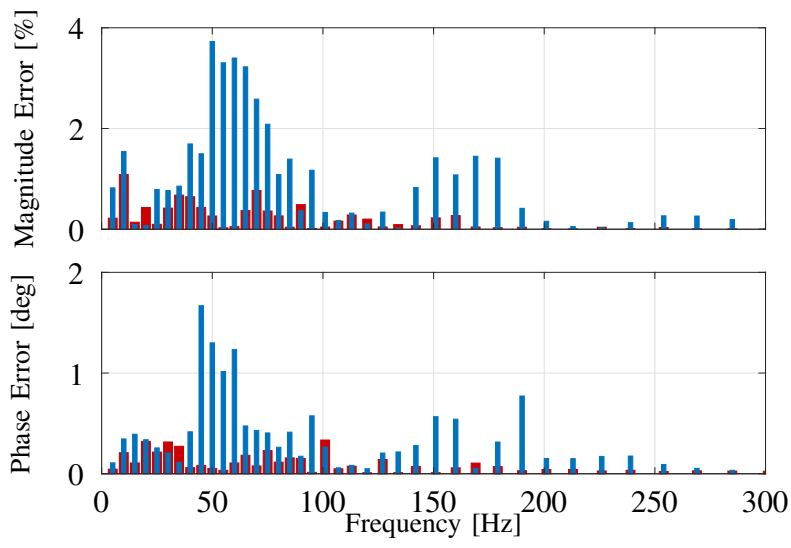

Figure 10. The admittance error analysis between the analytical models (only five perturbation components and two steady-state components) of the openloop (red) and the closed-loop (blue) schemes and the detailed simulation models in MATLAB/SIMULINK (all frequency components). The error is negligible for frequencies beyond that shown in the plot.

low error in most frequencies, as verified by the experimental results seen in Fig. 9.

\section{Impact of the Arm-Balancing Controller Parameters}

For the closed-loop computation of the insertion indices, the admittance shaping effect of variations in average and imbalance gains of the arm-balancing controller is investigated. To this end, the aforementioned proportional gains are varied by $\pm 25 \%$ and the dc-side admittance is computed by the analytical model and measured with the experimental setup. The results demonstrate good matching between the analytical model and the measurements, further proving the validity of the model.

The effect of the variations in $K_{\Sigma}$ is shown in Fig. 11 . It can be observed that an increase in the average gain of the arm-balancing controller, reduces the admittance magnitude at the resonance frequency around $60 \mathrm{~Hz}$ and augments the phase rotation. In addition, the said resonance frequency slightly decreases with an increase in $K_{\Sigma}$. Differences in the admittance magnitude and phase between the dc and the fundamental frequency can also be observed when $K_{\Sigma}$ is varied. Similarly, variations in the imbalance gain $K_{\Delta}$ affect the impedance shape around $60 \mathrm{~Hz}$, as seen in Fig. 12. However, this time, the resonance frequency slightly increases when $K_{\Delta}$ becomes greater.
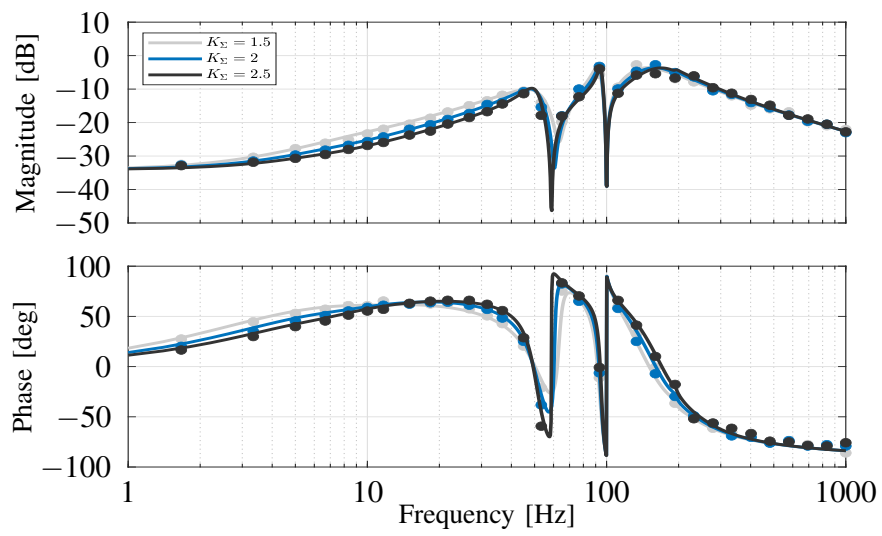

Figure 11. Bode diagram of the MMC dc-side admittance for different values of arm-balancing controller average gain $K_{\Sigma}$. The converter is operated with $d q$-frame ac-side current control and circulating current control with closedloop insertion index computation. The analytical models are shown by solid lines and the measurements by dots.
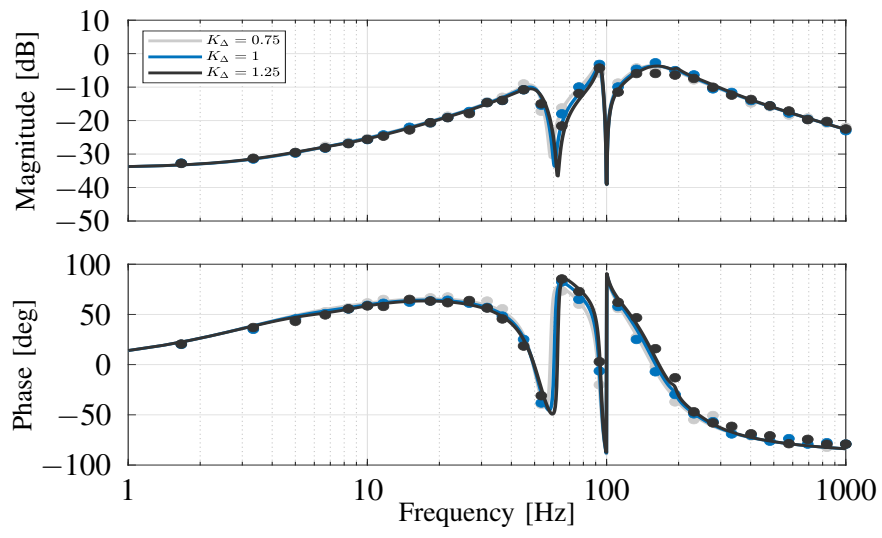

Figure 12. Bode diagram of the MMC dc-side admittance for different values of arm-balancing controller imbalance gain $K_{\Delta}$. The converter is operated with $d q$-frame ac-side current control and circulating current control with closed-loop insertion index computation. The analytical models are shown by solid lines and the measurements by dots.

\section{CONCLUSIONS}

In this paper, an analytical frequency-domain model is derived based on a combination of harmonic linearization and frequency-domain representation which calculates the admittance of an MMC seen from its dc-side. Different control 
schemes are incorporated into the model and the admittanceshaping effect of each control scheme and their control elements is assessed using Bode plots of the admittance. An analytical dc-side admittance model is developed for closedloop voltage control of the converter, where the measured sum-capacitor voltages are used in the computation of the insertion indices. The validity of the developed models is verified using experiments on a down-scaled prototype as well as a time-domain simulation model of the same system. It is shown that the results from the analytical model match closely those obtained from the experiment in spite of the complexities introduced to the admittance expression by the inclusion of control schemes and the nonlinearities. The results indicate the strong admittance shaping impact of the inner and outer control loops with the open-loop voltage control, as well as the arm-balancing control loop with the closed-loop voltage control. The developed model can be used in the future studies to assess the stability of the dc grid in point-to-point or multiterminal configurations, e.g., by means of impedancebased stability criteria.

\section{APPENDIX}

\section{A. Steady-State Components of the Converter Variables}

For the linear system considered in (43), the approximated steady-state values of the converter variables are given. These values appear as coefficients in $A_{p}$ and $B_{p}$.

Upper Arm Current: Assuming that the ac-side current and the circulating current track their references accurately, we obtain

$$
I_{u}(0)=i_{c}^{\star} \quad I_{u}\left(f_{1}\right)=\frac{I_{s}\left(f_{1}\right)}{2} \quad I_{s}\left(f_{1}\right)=\frac{i_{s d}^{\star}+j i_{s q}^{\star}}{2} .
$$

Upper Arm Sum Capacitor Voltage: the dc component of the sum capacitor voltage is approximately equal to the dc-bus voltage reference in steady-state. The fundamental frequency component of $V_{C u}^{\Sigma}$ is obtained evaluating (4) at the said frequency

$$
V_{C u}^{\Sigma}(0)=v_{d}^{\star} \quad V_{C u}^{\Sigma}\left(f_{1}\right)=\frac{I_{u}\left(f_{1}\right) N_{u}(0)+N_{u}\left(f_{1}\right) I_{u}(0)}{j \omega_{1} C} .
$$

Upper Arm Voltage Reference: With the closed-loop scheme, the ac- and the dc-sides of the converter are decoupled. This allows approximating the upper arm voltage reference as follows

$$
V_{u}^{\star}(0)=e_{1}^{\star} \quad V_{u}^{\star}\left(f_{1}\right)=-E\left(f_{1}\right)=e_{1}^{\star} / 2 .
$$

Upper Arm Insertion Index: Assuming that the voltage references $v_{s}^{\star}$ and $v_{c}^{\star}$ are generated in an open-loop fashion, i.e., $v_{s}^{\star}=e_{1}^{\star} \cos [\hat{\theta}]$ and $v_{c}^{\star}=v_{d}^{\star}$, and neglecting control system time delay, we obtain

$$
N_{u}(0)=\frac{1}{2} \quad N_{u}\left(f_{1}\right)=-\frac{e_{1}^{\star}}{2 v_{d}^{\star}} .
$$

\section{B. Perturbation Components of the Converter Variables}

The expressions describing the components of the upper arm current, upper arm voltage, and upper arm sum capacitor voltage at $f_{p} \pm f_{1}$ and $f_{p} \pm 2 f_{1}$ are given.
Upper Arm Current: Obtained similar to (23). Notice the absence of the zero sequence component of $i_{u}$ in the equations.

$$
\begin{aligned}
I_{u}\left(f_{p}-f_{1}\right) & =-\frac{V_{u}\left(f_{p}-f_{1}\right)}{j\left(\omega_{p}-\omega_{1}\right) L+R} \\
I_{u}\left(f_{p}+f_{1}\right) & =-\frac{V_{u}\left(f_{p}+f_{1}\right)}{j\left(\omega_{p}+\omega_{1}\right) L+R} \\
I_{u}\left(f_{p}-2 f_{1}\right) & =-\frac{V_{u}\left(f_{p}-2 f_{1}\right)}{j\left(\omega_{p}-2 \omega_{1}\right) L+R} \\
I_{u}\left(f_{p}+2 f_{1}\right) & =-\frac{V_{u}\left(f_{p}+2 f_{1}\right)}{j\left(\omega_{p}+2 \omega_{1}\right) L+R} .
\end{aligned}
$$

Upper Arm Sum Capacitor Voltage: Obtained similarly to $(25)$

$$
\begin{aligned}
V_{C u}^{\Sigma}\left(f_{p}-f_{1}\right)= & \frac{1}{j\left(\omega_{p}-\omega_{1}\right) C}\left[I_{u}\left(f_{p}-f_{1}\right) N_{u}(0)\right. \\
& +N_{u}\left(f_{p}-f_{1}\right) I_{u}(0)+I_{u}\left(f_{p}-2 f_{1}\right) N_{u}\left(f_{1}\right) \\
& +N_{u}\left(f_{p}-2 f_{1}\right) I_{u}\left(f_{1}\right)+I_{u}\left(f_{p}\right) \overline{N_{u}\left(f_{1}\right)} \\
& +N_{u}\left(f_{p}\right) \overline{\left.I_{u}\left(f_{1}\right)\right]} \\
V_{C u}^{\Sigma}\left(f_{p}+f_{1}\right)= & \frac{1}{j\left(\omega_{p}+\omega_{1}\right) C}\left[I_{u}\left(f_{p}+f_{1}\right) N_{u}(0)\right. \\
& +N_{u}\left(f_{p}+f_{1}\right) I_{u}(0)+I_{u}\left(f_{p}\right) N_{u}\left(f_{1}\right) \\
& +N_{u}\left(f_{p}\right) I_{u}\left(f_{1}\right)+I_{u}\left(f_{p}+2 f_{1}\right) \overline{N_{u}\left(f_{1}\right)} \\
& +N_{u}\left(f_{p}+2 f_{1}\right) \overline{\left.I_{u}\left(f_{1}\right)\right]} \\
V_{C u}^{\Sigma}\left(f_{p}-2 f_{1}\right)= & \frac{1}{j\left(\omega_{p}-2 \omega_{1}\right) C}\left[I_{u}\left(f_{p}-2 f_{1}\right) N_{u}(0)\right. \\
& +N_{u}\left(f_{p}-2 f_{1}\right) I_{u}(0)+I_{u}\left(f_{p}-f_{1}\right) \overline{N_{u}\left(f_{1}\right)} \\
& +N_{u}\left(f_{p}-f_{1}\right) \overline{\left.I_{u}\left(f_{1}\right)\right]} \\
V_{C u}^{\Sigma}\left(f_{p}+2 f_{1}\right)= & \frac{1}{j\left(\omega_{p}+2 \omega_{1}\right) C}\left[I_{u}\left(f_{p}+2 f_{1}\right) N_{u}(0)\right. \\
& +N_{u}\left(f_{p}+2 f_{1}\right) I_{u}(0)+I_{u}\left(f_{p}+f_{1}\right) N_{u}\left(f_{1}\right) \\
& \left.+N_{u}\left(f_{p}+f_{1}\right) I_{u}\left(f_{1}\right)\right] .
\end{aligned}
$$

Upper Arm Voltage: Obtained similar to (24)

$$
\begin{aligned}
V_{u}\left(f_{p}-f_{1}\right)= & V_{C u}^{\Sigma}\left(f_{p}-f_{1}\right) N_{u}(0)+N_{u}\left(f_{p}-f_{1}\right) V_{C u}^{\Sigma}(0) \\
& +V_{C u}^{\Sigma}\left(f_{p}-2 f_{1}\right) N_{u}\left(f_{1}\right) \\
& +N_{u}\left(f_{p}-2 f_{1}\right) V_{C u}^{\Sigma}\left(f_{1}\right) \\
& +V_{C u}^{\Sigma}\left(f_{p}\right) \overline{N_{u}\left(f_{1}\right)}+N_{u}\left(f_{p}\right) \overline{V_{C u}^{\Sigma}\left(f_{1}\right)} \\
V_{u}\left(f_{p}+f_{1}\right)= & V_{C u}^{\Sigma}\left(f_{p}+f_{1}\right) N_{u}(0)+N_{u}\left(f_{p}+f_{1}\right) V_{C u}^{\Sigma}(0) \\
& +V_{C u}^{\Sigma}\left(f_{p}\right) N_{u}\left(f_{1}\right)+N_{u}\left(f_{p}\right) V_{C u}^{\Sigma}\left(f_{1}\right) \\
& +V_{C u}^{\Sigma}\left(f_{p}+2 f_{1}\right) \overline{N_{u}\left(f_{1}\right)} \\
& +N_{u}\left(f_{p}+2 f_{1}\right) \overline{V_{C u}^{\Sigma}\left(f_{1}\right)} \\
V_{u}\left(f_{p}-2 f_{1}\right)= & V_{C u}^{\Sigma}\left(f_{p}-2 f_{1}\right) N_{u}(0)+N_{u}\left(f_{p}-2 f_{1}\right) V_{C u}^{\Sigma}(0) \\
& +V_{C u}^{\Sigma}\left(f_{p}-f_{1}\right) \overline{N_{u}\left(f_{1}\right)} \\
& +N_{u}\left(f_{p}-f_{1}\right) \overline{V_{C u}^{\Sigma}\left(f_{1}\right)} \\
V_{u}\left(f_{p}+2 f_{1}\right)= & V_{C u}^{\Sigma}\left(f_{p}+2 f_{1}\right) N_{u}(0)+N_{u}\left(f_{p}+2 f_{1}\right) V_{C u}^{\Sigma}(0) \\
& +V_{C u}^{\Sigma}\left(f_{p}+f_{1}\right) N_{u}\left(f_{1}\right) \\
& +N_{u}\left(f_{p}+f_{1}\right) V_{C u}^{\Sigma}\left(f_{1}\right) .
\end{aligned}
$$


Upper Arm Insertion Index: Obtained similar to (42), the perturbation frequency components of $n_{u}$ at $f_{p} \pm f_{1}$ and $f_{p} \pm$ $2 f_{1}$ including the effect of the arm-balancing controller, are calculated as

$$
\begin{aligned}
& \frac{N_{u}\left(f_{p}-2 f_{1}\right)}{e^{-j\left(\omega_{p}-2 \omega_{1}\right) T_{d}}}=\left[\frac{G_{c c}\left[j\left(\omega_{p}-2 \omega_{1}\right)\right]}{v_{C 0}^{\Sigma}} I_{u}\left(f_{p}-2 f_{1}\right)\right. \\
& +\left(\frac{K_{\Sigma}}{v_{C 0}^{\Sigma}}-\frac{V_{u}^{\star}(0)}{\left(v_{C 0}^{\Sigma}\right)^{2}}\right) V_{C u}^{\Sigma}\left(f_{p}-2 f_{1}\right) \\
& \left.-\left(\frac{K_{\Delta}}{v_{C 0}^{\Sigma}}-\frac{\overline{V_{u}^{\star}\left(f_{1}\right)}}{\left(v_{C 0}^{\Sigma}\right)^{2}}\right) V_{C u}^{\Sigma}\left(f_{p}-f_{1}\right)\right] \\
& N_{u}\left(f_{p}-f_{1}\right)=-e^{-j\left(\omega_{p}-\omega_{1}\right) T_{d}}\left[\frac{V_{C u}^{\Sigma}\left(f_{p}-f_{1}\right) V_{u}^{\star}(0)}{\left(v_{C 0}^{\Sigma}\right)^{2}}\right. \\
& +\frac{V_{C u}^{\Sigma}\left(f_{p}-2 f_{1}\right) V_{u}^{\star}\left(f_{1}\right)}{\left(v_{C 0}^{\Sigma}\right)^{2}} \\
& \left.+\frac{V_{C u}^{\Sigma}\left(f_{p}\right) \overline{V_{u}^{\star}\left(f_{1}\right)}}{\left(v_{C 0}^{\Sigma}\right)^{2}}\right] \\
& N_{u}\left(f_{p}+f_{1}\right)=-e^{-j\left(\omega_{p}+\omega_{1}\right) T_{d}}\left[\frac{V_{C u}^{\Sigma}\left(f_{p}+f_{1}\right) V_{u}^{\star}(0)}{\left(v_{C 0}^{\Sigma}\right)^{2}}\right. \\
& +\frac{V_{C u}^{\Sigma}\left(f_{p}+2 f_{1}\right) \overline{V_{u}^{\star}\left(f_{1}\right)}}{\left(v_{C 0}^{\Sigma}\right)^{2}} \\
& \left.+\frac{V_{C u}^{\Sigma}\left(f_{p}\right) V_{u}^{\star}\left(f_{1}\right)}{\left(v_{C 0}^{\Sigma}\right)^{2}}\right] \\
& \frac{N_{u}\left(f_{p}+2 f_{1}\right)}{e^{-j\left(\omega_{p}+2 \omega_{1}\right) T_{d}}}=\left[\frac{G_{c c}\left[j\left(\omega_{p}+2 \omega_{1}\right)\right]}{v_{C 0}^{\Sigma}} I_{u}\left(f_{p}+2 f_{1}\right)\right. \\
& +\left(\frac{K_{\Sigma}}{v_{C 0}^{\Sigma}}-\frac{V_{u}^{\star}(0)}{\left(v_{C 0}^{\Sigma}\right)^{2}}\right) V_{C u}^{\Sigma}\left(f_{p}+2 f_{1}\right) \\
& \left.-\left(\frac{K_{\Delta}}{v_{C 0}^{\Sigma}}-\frac{V_{u}^{\star}\left(f_{1}\right)}{\left(v_{C 0}^{\Sigma}\right)^{2}}\right) V_{C u}^{\Sigma}\left(f_{p}-f_{1}\right)\right] .
\end{aligned}
$$

\section{ACKNOWLEDGMENTS}

The first author's work has received funding from the European Union's Horizon 2020 research and innovation program under grant agreement No. 691714.

The authors would like to thank Dr. Panagiotis Bakas for his support and helpful comments during the experimental work.

\section{REFERENCES}

[1] A. Lesnicar and R. Marquardt, "An innovative modular multilevel converter topology suitable for a wide power range," in Proc. Power Tech Conf. Bologna, Italy, Jun. 2003.

[2] S. Allebrod, R. J. Hamerski, and R. Marquardt, "New transformerless, scalable modular multilevel converters for HVDC-transmission," in IEEE Power Electron. Spec. Conf., Jun. 2008, pp. 174-179.

[3] B. Jacobson, P. Karlsson, G. Asplund, L. Harnefors, and T. Jonsson, "VSC-HVDC transmission with cascaded two-level converters," in Proc. Cigré session, B4-B110, 2010.

[4] M. Winkelnkemper, A. Korn, and P. Steimer, "A modular direct converter for transformerless rail interties," in Proc. IEEE Int. Symp. Ind. Electron, Jul. 2010, pp. 562-567.

[5] M. Hagiwara, K. Nishimura, and H. Akagi, "A medium-voltage motor drive with a modular multilevel PWM inverter," IEEE Trans. Power Electron., vol. 25, no. 7, pp. 1786-1799, Jul. 2010.

[6] C. Zou, H. Rao, S. Xu, Y. Li, W. Li, J. Chen, X. Zhao, Y. Yang, and B. Lei, "Analysis of resonance between a VSC-HVDC converter and the ac grid," IEEE Trans. Power Electron., vol. 33, no. 12, pp. $10157-$ 10168 , Feb. 2018.

[7] N. Prabhu and K. R. Padiyar, "Investigation of subsynchronous resonance with VSC-based HVDC transmission systems," IEEE Trans. Power Del., vol. 24, no. 1, pp. 433-440, Jan. 2009.
[8] G. Pinares and M. Bongiorno, "Analysis and mitigation of instabilities originated from dc-side resonances in vsc-hvdc systems," IEEE Trans. Ind. Appl, vol. 52, no. 4, pp. 2807-2815, Apr. 2016.

[9] M. Barnes and A. Beddard, "Voltage source converter HVDC links the state of the art and issues going forward," Energy Procedia, vol. 24, pp. 108-122, Jan. 2012.

[10] Y. Li, G. Tang, J. Ge, Z. He, H. Pang, J. Yang, and Y. Wu, "Modeling and damping control of modular multilevel converter based dc grid," IEEE Trans. Power Syst., vol. 33, no. 1, pp. 723-735, Jan. 2018.

[11] L. Harnefors, X. Wang, A. G. Yepes, and F. Blaabjerg, "Passivity-based stability assessment of grid-connected VSCs-an overview," IEEE $J$. Emerg. Sel. Top. Power Electron., vol. 4, no. 1, pp. 116-125, Mar. 2016.

[12] G. Stamatiou and M. Bongiorno, "Stability analysis of two-terminal VSC-HVDC systems using the net-damping criterion," IEEE Trans. Power Del., vol. 31, no. 4, pp. 1748-1756, Jan. 2016.

[13] J. Sun, "Impedance-based stability criterion for grid-connected inverters," IEEE Trans. Power Electron., vol. 26, no. 11, pp. 3075-3078, Nov. 2011.

[14] — "Small-signal methods for ac distributed power systems-a review," IEEE Trans. Power Electron., vol. 24, no. 11, pp. 2545-2554, Aug. 2009.

[15] M. Beza, M. Bongiorno, and G. Stamatiou, "Analytical derivation of the ac-side input admittance of a modular multilevel converter with openand closed-loop control strategies," IEEE Trans. Power Del., vol. 33, no. 1, pp. 248-256, May 2018.

[16] J. Khazaei, M. Beza, and M. Bongiorno, "Impedance analysis of modular multi-level converters connected to weak ac grids," IEEE Trans. Power Syst., vol. 33, no. 4, pp. 4015-4025, Jul. 2018.

[17] J. Sun and H. Liu, "Sequence impedance modeling of modular multilevel converters," IEEE J. Emerg. Sel. Top. Power Electron., vol. 5, no. 4, pp. 1427-1443, Dec. 2017.

[18] J. Lyu, Q. Chen, and X. Cai, "Impedance modeling of modular multilevel converters by harmonic linearization," in 2016 IEEE 17th Workshop on Control and Modeling for Power Electronics (COMPEL), Jun. 2016, pp. $1-6$.

[19] L. Bessegato, L. Harnefors, K. Ilves, and S. Norrga, "A method for the calculation of the ac-side admittance of a modular multilevel converter," IEEE Trans. Power Electron., vol. 34, no. 5, pp. 4161-4172, May 2019

[20] L. Bessegato, K. Ilves, L. Harnefors, and S. Norrga, "Effects of control on the ac-side admittance of a modular multilevel converter," IEEE Trans. Power Electron., vol. 34, no. 8, pp. 7206-7220, Aug. 2019.

[21] Z. Zhang, Z. Xu, Y. Xue, and G. Tang, "Dc-side harmonic currents calculation and dc-loop resonance analysis for an LCC-MMC hybrid HVDC transmission system," IEEE Trans. Power Del., vol. 30, no. 2, pp. 642-651, Jan. 2015.

[22] J. Lyu, X. Zhang, Z. Ma, and X. Cai, "A novel dc-side-port impedance modeling of modular multilevel converters based on harmonic state space method," in 2018 International Power Electronics Conference (IPEC-Niigata 2018 -ECCE Asia), May 2018, pp. 4162-4167.

[23] G. Stamatiou, M. Beza, M. Bongiorno, and L. Harnefors, "Analytical derivation of the dc-side input admittance of the direct-voltage controlled modular multilevel converter," IET Gener., Transmiss. Distrib., vol. 11, no. 16, pp. 4018-4030, Nov. 2017.

[24] L. Xu, L. Fan, and Z. Miao, "Dc impedance-model-based resonance analysis of a VSC-HVDC system," IEEE Trans. Power Del., vol. 30, no. 3, pp. 1221-1230, Nov. 2015.

[25] Ö. C. Sakinci and J. Beerten, "Input admittance calculation of the modular multilevel converter using a linearized dynamic phasor model," in IECON 2019 - 45th Annual Conference of the IEEE Industrial Electronics Society, vol. 1, Oct. 2019, pp. 4831-4836.

[26] K. Ji, H. Pang, J. Yang, and G. Tang, "Dc side harmonic resonance analysis of MMC-HVDC considering wind farm integration," IEEE Trans. Power Del., in print, 2020.

[27] K. Ji, G. Tang, J. Yang, Y. Li, and D. Liu, "Harmonic stability analysis of MMC-based dc system using dc impedance model," IEEE J. Emerg. Sel. Top. Power Electron., vol. 8, no. 2, pp. 1152-1163, Jun. 2020.

[28] Z. Xu, B. Li, L. Han, J. Hu, S. Wang, S. Zhang, and D. Xu, "A complete HSS-based impedance model of MMC considering grid impedance coupling," IEEE Trans. Power Electron., vol. 35, no. 12, pp. 12929 12948, May 2020.

[29] Z. Li, Z. Wang, Y. Wang, T. Yin, N. Mei, B. Yue, and W. Lei, "Accurate impedance modeling and control strategy for improving the stability of dc system in multiterminal MMC-based dc grid," IEEE Trans. Power Electron., vol. 35, no. 10, pp. 10026-10049, Feb. 2020.

[30] K. Sharifabadi, L. Harnefors, H.-P. Nee, S. Norrga, and R. Teodorescu, Design, Control and Application of Modular Multilevel Converters for HVDC Transmission Systems. Chichester, UK: John Wiley \& Sons Ltd, 2016. 
[31] A. Nami, J. Liang, F. Dijkhuizen, and G. D. Demetriades, "Modular multilevel converters for HVDC applications: Review on converter cells and functionalities," IEEE Trans. Power Electron., vol. 30, no. 1, pp. 18-36, Jan. 2015.

[32] L. Harnefors, A. Antonopoulos, S. Norrga, L. Angquist, and H.-P. Nee, "Dynamic analysis of modular multilevel converters," IEEE Trans. Ind. Electron., vol. 60, no. 7, pp. 2526-2537, Jul. 2013.

[33] M. Saeedifard and R. Iravani, "Dynamic performance of a modular multilevel back-to-back HVDC system," IEEE Trans. Power Del., vol. 25, no. 4, pp. 2903-2912, Oct. 2010.

[34] A. Antonopoulos, L. Angquist, and H. Nee, "On dynamics and voltage control of the modular multilevel converter," in 13th European Conference on Power Electronics and Applications, 2009, pp. 1-10.

[35] Z. Li, P. Wang, Z. Chu, H. Zhu, Y. Luo, and Y. Li, "An inner current suppressing method for modular multilevel converters," IEEE Trans. Power Electron., vol. 28, no. 11, pp. 4873-4879, Jan. 2013

[36] M. Cespedes and J. Sun, "Impedance modeling and analysis of gridconnected voltage-source converters," IEEE Trans. Power Electron., vol. 29, no. 3, pp. 1254-1261, 2014.

[37] L. Bessegato, A. Narula, P. Bakas, and S. Norrga, "Design of a modular multilevel converter prototype for research purposes," in 2018 20th European Conference on Power Electronics and Applications (EPE'18 ECCE Europe), 2018, pp. 1-10.

[38] K. Ilves, L. Harnefors, S. Norrga, and H.-P. Nee, "Analysis and operation of modular multilevel converters with phase-shifted carrier PWM," IEEE Trans. Power Electron., vol. 30, no. 1, pp. 268-283, Jan. 2015.

[39] H. Wu and X. Wang, "Dynamic impact of zero-sequence circulating current on modular multilevel converters: Complex-valued ac impedance modeling and analysis," IEEE J. Emerg. Sel. Top. Power Electron., vol. 8, no. 2, pp. 1947-1963, Jun. 2020

[40] A. Bayo-Salas, T. Roose, and J. Beerten, "Frequency-domain modeling and assessment of $\mathrm{AC}$ and $\mathrm{DC}$ electromagnetic stability in MMC-based VSC-HVDC links," in IECON 2018 - 44th Annual Conference of the IEEE Industrial Electronics Society, Oct. 2018, pp. 6015-6020.

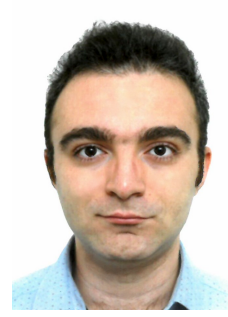

Mehrdad Nahalparvari (S'19) received the M.Sc. degree in power electronics from Tampere University, Tampere, Finland, in 2019. He is currently working towards the Ph.D. degree in electrical engineering at KTH Royal Institute of Technology, Stockholm, Sweden.

His research interests include modeling and control of power electronic converters.

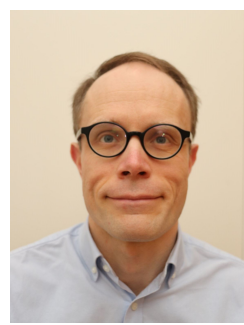

Staffan Norrga (S'00-M'06) was born in Lidingö, Sweden, in 1968. He received the M.Sc. degree in applied physics from Linköping Institute of Technology, Linköping, Sweden, in 1993 and the Ph.D. degree in electrical engineering from the Royal Institute of Technology (KTH), Stockholm, Sweden, in 2005 .

Between 1994 and 2011, he worked as a Development Engineer at $\mathrm{ABB}$ in Västerås, Sweden, in various power-electronics-related areas such as railway traction systems and converters for HVDC power transmission systems. He currently holds a position as associate professor in power electronics at KTH.

His research interests include power electronics and its applications in power grids, renewables and electric vehicles. He is the inventor or co-inventor of more than 10 granted patents and has authored or co-authored more than 100 scientific papers published at international conferences or in journals.

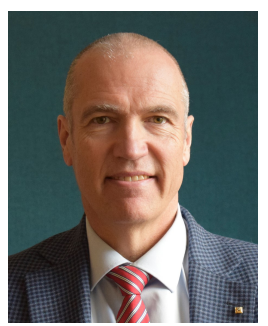

Hans-Peter Nee (S'91-M'96-SM'04-F'18) was born in Västerås, Sweden, in 1963. He received the M.Sc., Licentiate, and Ph.D. degrees in electrical engineering from the Royal Institute of Technology (KTH), Stockholm, Sweden, in 1987, 1992, and 1996, respectively.

Since 1999, he has been a Professor of power electronics with the Department of Electrical Engineering, $\mathrm{KTH}$. His research interests include power electronic converters, semiconductor components, and control aspects of utility applications, such as flexible ac transmission systems and high-voltage direct-current transmission, and variable-speed drives.

Dr. Nee was a member of the Board of the IEEE Sweden Section for many years and was the Chair of the Board from 2002 to 2003. He is also a member of the European Power Electronics and Drives Association and is involved with its Executive Council and International Scientific Committee.

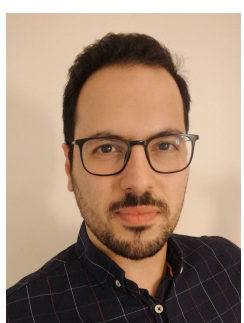

Mohsen Asoodar (S'18) received his M.Sc. degree in electrical engineering from KTH Royal Institute of Technology, Stockholm, Sweden, in 2014. He joined ABB Corporate Research in Västerås, Sweden as a research scientist in 2014, and later served as a research and development engineer in $\mathrm{ABB}$ FACTS, Västerås, Sweden. He is currently working at Hitachi-ABB Power Grids, Sweden, within the technology and solutions development team as a senior research and development engineer.

Mohsen's research interests include design, control, and grid integration of power electronic systems.

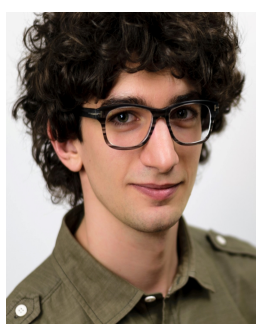

Luca Bessegato (S'14-S'19) received the M.S. degree in electronic engineering from the University of Padova, Padova, Italy, in 2014, and the Ph.D. degree in electrical engineering from KTH Royal Institute of Technology, Stockholm, Sweden, in 2019.

His research interests include modeling and control of modular multilevel converters and STATCOMs. 